\title{
Peas, please! Food familiarization though picture books helps parents introduce vegetables into preschoolers' diets
}

Article

Accepted Version

Creative Commons: Attribution-Noncommercial-No Derivative Works 4.0

Owen, L. H., Kennedy, O. B., Hill, C. and Houston-Price, C. (2018) Peas, please! Food familiarization though picture books helps parents introduce vegetables into preschoolers' diets. Appetite, 128. pp. 32-43. ISSN 0195-6663 doi: https://doi.org/10.1016/j.appet.2018.05.140 Available at https://centaur.reading.ac.uk/72923/

It is advisable to refer to the publisher's version if you intend to cite from the work. See Guidance on citing.

To link to this article DOI: http://dx.doi.org/10.1016/j.appet.2018.05.140

Publisher: Elsevier

All outputs in CentAUR are protected by Intellectual Property Rights law, including copyright law. Copyright and IPR is retained by the creators or other copyright holders. Terms and conditions for use of this material are defined in the End User Agreement.

www.reading.ac.uk/centaur 
Central Archive at the University of Reading

Reading's research outputs online 
Peas, please! Food familiarization through picture books helps parents introduce vegetables into preschoolers' diets

Laura H. Owen

School of Psychology and Clinical Language Sciences, University of Reading

Orla B. Kennedy

Hugh Sinclair Human Nutrition Unit, Dept. of Food and Nutritional Sciences, University of Reading

Claire Hill

School of Psychology and Clinical Language Sciences, University of Reading

\section{Carmel Houston-Price}

School of Psychology and Clinical Language Sciences, University of Reading

Keywords: visual familiarity, taste exposure, fruit \& vegetables, picture books, children

Please address correspondence to: Professor Carmel Houston-Price, School of Psychology and Clinical Language Sciences, University of Reading, Earley Gate, Whiteknights, Reading RG6 6AL, UK. Email: c.houston-price@ reading.ac.uk

Acknowledgements: This research was funded by an award to the last author by the Economic and Social Research Council (Award Ref: RES-000-22-3891). 


\begin{abstract}
Repeated taste exposure is an established means of increasing children's liking and intake of fruit and vegetables. However, parents find it difficult to offer children disliked foods repeatedly, often giving up after a few attempts. Studies show that familiarizing children to fruit and vegetables through picture books can increase their interest in tasting targeted foods. This study explored whether looking at picture books before providing foods to taste improved the outcomes of a home-delivered taste exposure regime. Parents of 127 toddlers (aged 21-24 months) identified two 'target' foods they wanted their child to eat (1 fruit, 1 vegetable). Families were randomly assigned to one of three groups. Parents and children in two experimental groups looked at books about either the target fruit or vegetable every day for two weeks; the control group did not receive a book. Parents in all three groups were then asked to offer their child both target foods every day during a 2-week taste-exposure phase. Parental ratings of children's liking and consumption of the foods were collected at baseline, immediately following taste-exposure (post-intervention), and 3 months later (follow-up). In all groups, liking of both foods increased following taste exposure and remained above baseline at follow-up (all $p s<.001$ ). In addition, compared to the control group who experienced only taste exposure, looking at vegetable books enhanced children's liking of their target vegetable post-intervention $(p<.001)$ and at follow-up $(\mathrm{p}<.05)$, and increased consumption of the vegetable at follow-up $(p<.01)$. Exposure to vegetable books was also associated with smaller increases in neophobia and food fussiness over the period of the study compared to controls ( $p s<.01$ ), suggesting that picture books may have positive, long-term impacts on children's attitudes towards new foods.
\end{abstract}


Introduction

The earlier healthy eating habits begin, the greater the health benefits (Maynard, Gunnell, Emmett, Frankel \& Davey Smith, 2003). In part, this is due to early dietary variety predicting the variety of foods eaten in later childhood, adolescence and adulthood (Ashcroft, Semmler, Carnell, van Jaarsveld \& Wardle, 2008; Devine, Connors, Bisogni \& Sobal, 1998; Nicklaus, Boggio, Chabanet \& Issanchou, 2005; Skinner, Carruth, Bounds, Ziegler \& Reidy, 2002). Unfortunately, less than one in 10 British children eats sufficient fruit and vegetables (National Diet \& Nutrition Survey, 2014). Intake of green vegetables is especially low during the preschool years (Cooke et al., 2004; Fox, Condon, Briefel, Reidy \& Deming, 2010), likely due to children's preference for bland, sweet foods (Wardle \& Cooke, 2008; Ventura \& Mennella, 2011) and dislike of sour and bitter tastes (Reed \& Knaapila, 2010). Techniques that increase children's fruit and vegetable intake therefore merit attention. This study explores whether familiarizing children to foods in picture books immediately before they are offered the foods to taste might prove one such technique.

Considerable effort has been directed toward educating parents and children about the benefits of healthy eating through government and health service campaigns (e.g. 5 A Day, NHS, 2003; Change 4 Life, Public Health England, 2009; Healthy Start, Department of Health, Social Services \& Public Safety, 2011). However, the key predictors of what children eat are whether foods are familiar and whether they are liked, rather than whether they are known to be healthy (Domel et al., 1996; Gibson, Wardle \& Watts, 1998; Cooke, 2007; Wardle \& Cooke, 2008). Moreover, food preferences are established in the infant and preschool years, before education about nutrition is usually feasible (Skinner et al., 2002; Cooke et al., 2004; but see Gripshover \& Markman, 2013).

Another approach is to directly manipulate young children's familiarity with and liking of fruits and vegetables. Infants tend to be more accepting of new foods than older preschoolers, who often reject unfamiliar foods without tasting them, a phenomenon known as 'food neophobia' (Birch, McPhee, Shoba, Pirok \& Steinberg, 1987; Raudenbush \& Frank, 1999). Food neophobia peaks around two years of age and typically continues until four to six years (Addessi, Galloway, Visalberghi \& Birch, 2005; Cashdan, 1994; Cooke, Wardle \& Gibson, 2003), impeding children's 
familiarity with new foods throughout this period (Tuorila \& Mustonen, 2010). Parents are therefore increasingly encouraged to expose infants to healthy foods from the outset, by providing repeated opportunities to taste vegetables at weaning, for example (First Steps Nutrition Trust, 2017). Experimental studies have shown that repeated taste exposures to fruits and vegetables can increase both infants' and preschoolers' intake and liking of these foods, suggesting that children benefit from food familiarity throughout the neophobic period (e.g. Birch \& Marlin, 1982; Birch et al., 1987; Caton, et al., 2013; de Wild, de Graaf \& Jager, 2013; Fildes, van Jaarsveld, Wardle \& Cooke, 2013; Hausner, Olsen \& Moller, 2012; Wardle et al., 2003a, 2003b; for recent reviews, see Cooke, 2007; Keller, 2014). For example, Wardle et al. (2003a) asked parents to offer preschoolers (aged 2 - 6 years) a taste of a target vegetable every day for two weeks; children consumed $64 \%$ more of the vegetable in a post-intervention taste test than they did at baseline.

While repeated taste exposure is clearly effective for introducing new foods, it requires considerable determination to administer. Changes in food liking and consumption are a function of the frequency with which foods are offered (Caton, et al., 2013; Wardle et al., 2003b), and some studies suggest that 8 to 15 tastes may be needed to induce liking and acceptance in young children (e.g. Birch \& Marlin, 1982; Birch et al., 1987; Wardle et al., 2003a; Lakkakula, Geaghan, Zanovec, Pierce \& Tuuri 2010). In the home environment, the responsibility for providing sufficient taste opportunities lies with parents, who act as 'gatekeepers' to food familiarity through their control over the range of foods available. Unfortunately, parents' sensitivity to children's likes and dislikes and their desire to avoid mealtime battles means that they are often not willing or able to show the persistence required for successful food introduction (Carruth \& Skinner, 2000; Carruth, Ziegler, Gordon \& Barr, 2004). Carruth et al. (2004) noted that three to five taste exposures were all that most parents could manage. Parents' own food preferences further exacerbate the difficulty of adhering to repeated taste paradigms; children's opportunities to taste fruit and vegetables are constrained by their mothers' likes and dislikes and purchases of foods (Busick, Brooks, Pernecky, Dawson \& Petzoldt, 2008; Worobey, Ostapkovich, Yudin \& Worobey, 2010). If children's low level of consumption of healthy foods - and vegetables, in particular - is to change, parents clearly need to be assisted in their efforts to introduce these. 
This study investigated whether parents' attempts to introduce fruit and vegetables through repeated taste exposure were helped by prior visual familiarization to foods - specifically, a period spent looking at picture books about foods immediately before these were offered to children to taste. Book sharing is an activity enjoyed by parents and young children from the first year of life, through which children's developing understanding of the world is supported across a variety of domains (Horst \& Houston-Price, 2015). The likelihood of picture books influencing children's food preferences varies according to differing theoretical perspectives on the mechanisms by which food familiarity supports acceptance. One approach considers food neophobia a biologically-determined concern about the safety of unfamiliar foods (Cashdan, 1998; Rozin, 1976); repeated opportunities to taste a food condition acceptance of the food through the lack of aversive consequences to eating it. If such 'learned safety' (Kalat \& Rozin, 1973; Rozin, 1976) is the sole mechanism through which repeated taste exposure supports acceptance, familiarization regimes that do not involve tasting the food - such as visual familiarization - should not succeed. However, research in other domains has shown that 'mere exposure' can elicit positive attitudes towards a stimulus merely by enhancing its familiarity (Butler \& Berry, 2004; Zajonc, 1968, 2001). As described by Zajonc (2001, p.224), the "benign experience of repetition can in and of itself enhance positive affect". If mere exposure plays a role in the development of food preferences, methods of familiarizing children with foods that do not involve tasting may prove effective. Given that liking of a food's taste is influenced by its appearance (\& smell, sound and texture; Dazeley \& Houston-Price, 2014; Dazeley, Houston-Price \& Hill, 2012; Heath, HoustonPrice \& Kennedy, 2011), it is plausible that visual familiarity may contribute to food acceptance.

Until recently, little research has directly explored the impact of visual familiarity on food intake or liking. The influence of branding, videos, story books and advertisements on children's attitudes, preferences and intake of targeted foods is well documented (e.g. Borzekowski \& Robinson, 2001; Lowe, Horne, Tapper, Bowdery \& Egerton, 2004; Robinson, Borzekowski, Matheson \& Kraemer, 2007; Buijzen, Schuurman \& Bomhof, 2008; De Droog, Buijzen \& Valkenburg, 2014). However, the materials used in such studies often involve peer modelling and/or rewards for consumption, making it difficult to disentangle the effects of mere exposure, conditioning, social facilitation, social referencing and reward processes. Other work has explored 
how visual familiarity with foods influences children's interest in looking at foods. For example, Houston-Price, Burton, Hickinson et al. (2009a) reported that looking at picture books about fruits and vegetables caused 17- to 27-month-old toddlers to spend longer attending to familiarized foods in a subsequent laboratory visual-preference task. Heath, Houston-Price \& Kennedy (2010) demonstrated the graded nature of this effect: initially unfamiliar foods were most susceptible to familiarization through picture books, followed by disliked foods, and then liked foods. However, while such work shows that infants' interest in looking at foods is enhanced by seeing these in picture books, parallel influences on children's food intake are not a given.

An early study by Birch et al. (1987) concluded that such an influence was unlikely. Birch and colleagues presented 2- to 5-year-old children with 5, 10 or 15 taste exposures or visual exposures to six unfamiliar fruits. Although looking at foods enhanced children's ratings of how much they liked the foods' appearance, only tasting foods enhanced ratings of their taste, leading Birch et al. to conclude that there was no cross-modal facilitation from visual familiarity to food liking. This finding does not preclude other potential benefits to visual familiarity, however. For example, if foods become more visually appealing as they become more familiar (Birch et al., 1987; Heath et al., 2010; Houston-Price et al., 2009a), children might become more willing to taste them.

Houston-Price, Butler \& Shiba (2009b) conducted a preliminary investigation into this question. Parents of 20 toddlers aged 21 to 24 months were sent one of two books about four target foods, which they read with their child every day for two weeks. Books contained photographs of fruits and vegetables that varied in prior familiarity (e.g. carrots vs. radishes), alongside information about how the foods grow, what they look like inside, how they are prepared and what they taste like. In a subsequent laboratory 'willingness to taste' test, children were offered a plate of the vegetables, and then the fruits, shown in the two books. Children displayed typically neophobic responses, tasting fewer of the initially unfamiliar foods. Their willingness to taste unfamiliar fruits was enhanced by seeing these in books, however, suggesting that visual exposure might help children to overcome their natural aversion towards unfamiliar foods. In a similar study, Heath, Houston-Price \& Kennedy (2014) asked parents and 19- to 26-month old toddlers to look at a book about a food that was liked, disliked or unfamiliar to the child. In a 'willingness to taste' test, 
children required less persuasion to eat the exposed food, and ate more of this, than of a matched control food. Effects were again strongest for food that were initially unfamiliar or disliked.

The current study builds on this work by exploring whether sharing picture books with toddlers immediately prior to engaging in a home-based repeated taste exposure intervention supports parents in introducing fruits and vegetables into children's diets. As in previous studies finding positive outcomes, we invited participation from families with children approaching the end of their second year. Parents were asked to identify two target foods, one fruit and one vegetable, which their child did not eat, but which they would like them to eat. In a randomized controlled trial design, families were allocated to one of three groups: a 'fruit book' group, a 'vegetable book' group, or a control group. Parents in the two experimental groups were asked to look at a picture book about the child's target fruit or vegetable every day for two weeks. This was followed by a two-week taste-exposure phase; parents in all three groups were asked to offer their child daily tastes of both target foods, which they received through home deliveries. This design allowed us to establish any effects of visual familiarization over and above those of repeated taste exposure, and to isolate the books' specific impact on the food targeted, controlling for any nonspecific effects of participation in shared book-reading. To test for immediate and longer-term effects of the intervention, measures of children's liking and consumption of the target foods, and their attitudes towards foods in general, were collected prior to the intervention, immediately following the taste-exposure phase, and three months later. In contrast to previous similar work, measures were obtained through parent-report questionnaires completed at home rather than experimenter ratings collected in a laboratory, providing a potentially more ecologically-valid index of the intervention's impact on children's food acceptance. We hypothesized that children who had seen picture books would show greater increases in liking and consumption of the specific food to which they had received visual familiarization than children who first encountered that food in the taste-exposure phase. In addition, we collected a range of background and demographic measures for each participating family, enabling us to explore whether the effectiveness of visual familiarization was moderated by individual differences, and whether the influence of the picture books extended beyond children's attitudes towards targeted foods. 
Methods

Participants

Families of 127 children (61 males) aged 18 to 24 months (mean age at baseline $=21.60$ months; $\mathrm{SD}=1.58$ ) were recruited from the University's Child Development Group's database of parents who had expressed an interest in participating in research with their child $(n=103)$, or via adverts placed on the parenting websites Mumsnet and BabyCentre $(n=13)$, flyers placed in local nurseries $(n=7)$ or word of mouth $(n=4)$. Families were randomly assigned to one of three experimental groups: a 'fruit book' group ( $n=42 ; 22$ males; mean age at baseline $=21.82$ months, $\mathrm{SD}=1.59)$; a 'vegetable book' group ( $n=46 ; 22$ males; mean age at baseline $=21.61$ months, SD $=1.60)$; or a control group $(n=39 ; 17$ males; mean age at baseline $=21.27$ months, $\mathrm{SD}=1.44)$.

Of the 127 parents who returned questionnaires at baseline, 105 completed the visual familiarization and taste-exposure phases of the intervention and returned the questionnaires sent out immediately post-intervention (mean age of children post-intervention $=23.54$ months, $\mathrm{SD}=$ 1.68). The distribution of the 22 non-respondents between groups did not differ from that expected by chance, $\chi^{2}(2)=2.07, \mathrm{p}=.36$, Cramer's $\mathrm{V}=.13$ (fruit book group, $n=8$; vegetable book group, $n=10$; control group: $n=4$ ). Seventy-eight parents returned follow-up questionnaires three months later (including 1 who did not respond post-intervention; mean age of children at followup $=26.98$ months, $\mathrm{SD}=1.57)$. The distribution of the 28 families who dropped out between postintervention and follow-up again did not differ from chance, $\chi^{2}(2)=4.00, p=.14$, Cramer's V $=$ .20 (fruit book group, $n=13$; vegetable book group, $n=9$; control group: $n=6$ ).

The study was scrutinized and allowed to proceed by the University of X's Research Ethics Committee (Reference No. REC 10/01) and was carried out in accordance with the Code of Ethics of the World Medical Association (Declaration of Helsinki). Parents (in all cases, mothers) gave informed consent to both their and their child's participation. 
Measures

\section{Demographic Questionnaire}

Background information was collected on the following: child's age, gender and ethnic origin; parents' educational level, marital status, and household income; number of children living at home; frequency of family meals; and parents' purchases of fruit and vegetables.

\section{Fruit \& Vegetable Familiarity \& Liking Questionnaire (FVFLQ) (Heath et al., 2014)}

Parents rated how much their child liked a list of fruits and vegetables, including the target foods, on a six-point scale from 'strongly likes' (coded as 5) to 'strongly dislikes' (1) or 'never tried' (0). For the list of foods included in this questionnaire, see Appendix I.

\section{Child Food Frequency Questionnaires (CFFQ) (Livingstone, 2010)}

Parents were asked how frequently their child consumed a portion of each of 11 fruits and 14 vegetables, including the target foods (see Appendix II). Appropriate child portion sizes were indicated for each food (NHS, 2011). There were 11 response options ranging from 'never or less than once a month' to ' $3+$ times per day'. Responses were recoded into portions per day using calculations based on Beck, Nicklaus, Jensen, Issanchou \& Kidmose (2013) (e.g., 2 times/wk was recoded as .29 portions/day) and summed to produce total daily fruit and vegetable intake.

\section{Child Food Neophobia Scale (CFNS) (Pliner, 1994)}

Parents completed the CFNS as an index of their child's attitudes towards new foods. Parents were asked to indicate how much they agreed or disagreed with six statements by selecting among four response options ranging from 'strongly agree' (coded as 4) to 'strongly disagree' (coded as 1). Negatively-worded statements were reverse coded and scores were summed to produce a total score for each child, with higher total scores indicating greater food neophobia.

Children's Eating Behaviour Questionnaire: Food Fussiness subscale (CEBQ:FF) (Wardle, Guthrie, Sanderson \& Rapoport, 2001) 
The CEBQ:FF subscale was used as an index of children's food fussiness. Parents indicated how well six statements described their child using five response options ranging from 'never' (coded as 1) to 'always' (coded as 5). Negatively-worded statements were reverse coded, and scores were summed to produce a single score for each child, with higher scores indicating greater fussiness.

\section{Procedure}

Upon recruitment, parents were asked to specify one fruit and one vegetable that they wanted their child to eat but that their child refused to eat. The two foods identified were designated the target foods for that child (see Appendix III for foods selected by parents). A number of parents were unable to identify a disliked fruit $(\mathrm{N}=21)$ or vegetable $(\mathrm{N}=19)$; these parents were asked to name instead an unfamiliar food that they wanted their child to eat. Of the final set of target foods, $85 \%$ of fruits and $89 \%$ of vegetables were reported to be disliked; the remainder were unfamiliar.

\section{Baseline Questionnaires}

Parents were sent a set of questionnaires by mail to return in a prepaid envelope or were emailed a link to the same questionnaires through the Bristol Online Surveys Tool, as requested. Measures collected at baseline included: Demographic Questionnaire; Fruit and Vegetable Familiarity \& Liking Questionnaire (Heath et al., 2014); Child Food Frequency Questionnaire (Livingstone, 2010); Child Food Neophobia Scale (Pliner, 1994); Children's Eating Behaviour Questionnaire: Food Fussiness subscale (Wardle et al., 2001).

\section{Visual Familiarization Phase}

After the baseline questionnaires were returned, parents of children in the 'fruit book' and 'vegetable book' groups were sent a picture book about their child's target fruit or vegetable, respectively. Each book contained 6 pages of color photographs and basic information about the food, presented as a 'farm to fork' story showing how the food grows, how it is sold in shops, and what it looks like when it is cut open, prepared and served (see Figure 1 for an example). Parents were asked to look at the book with their child for five minutes every day for 14 consecutive days. Parents were told that the aim of the book was to increase their child's familiarity with the food 
and that they could use their own words in addition to those provided. Families in the control group did not receive a book and were told that they would be contacted two weeks later.

\section{$<$ Figure $1>$}

\section{Taste-Exposure Phase}

Following the visual familiarization phase, families in all conditions participated in two weeks of taste exposure. Parents were asked to offer their child a taste of both target foods every day for 15 consecutive days. Families received home deliveries of both foods three times during this period (on approx. the $1^{\text {st }}, 6^{\text {th }}$ and $11^{\text {th }}$ day); each delivery provided enough for at least five servings. Fresh foods were provided where possible but tinned, frozen or dried foods were substituted if fresh foods were not available. Parents were asked to provide a child-sized portion of each food every day, defined as the amount that would fit into the palm of their child's hand (NHS, 2011). Parents were invited to prepare the foods as they preferred, and to provide them at whatever time of day was convenient, as a snack or part of a meal. However, they were asked to prepare foods in the same way each day (e.g. boiled carrots every day, rather than boiled one day and raw the next) and to avoid mixing them with other foods, so that that the child knew what they were eating.

On each day of taste exposure, parents were asked to record in a daily diary whether they had been able to offer their child a taste of each food and, if so, whether the child had tasted it. The same diaries were used to collect measures of parents' experiences and children's behaviors on each occasion foods were offered during this phase. Analysis of these diary measures is reported in a separate publication (see Houston-Price, Owen, Kennedy \& Hill, in prep.).

\section{Post-Intervention Questionnaires}

Upon completion of the taste-exposure phase, parents completed and returned the same set of questionnaires as at baseline (except the Demographic Questionnaire), again by post or online. The mean time between baseline and post-intervention questionnaire completion was 8.24 weeks $(\mathrm{SD}=2.10)$, reflecting the 4-week combined duration of the visual and taste exposure phases and the time involved in sending out books and questionnaires, and completing and returning these. 


\section{Follow-Up Questionnaires}

Approximately three months later, parents were provided with a final set of questionnaires to complete and return, by post or online. The same measures were collected as at post-intervention. The mean time between post-intervention and follow-up questionnaire completion was 15.02 weeks $(\mathrm{SD}=1.98)$. After questionnaires had been returned, children in the control group were sent a book about their target fruit or vegetable to thank them for their participation.

\section{Data Analysis}

The primary experimental hypotheses, that children would show greater increases in liking and consumption of foods to which they had received prior visual familiarization, were tested using mixed ANOVA. Changes in liking were explored using a 3 (Group: Vegetable Book, Fruit Book, Control) x 3 (Time: Baseline, Post-intervention, Follow-up) mixed ANOVA for each food. Changes in consumption were explored using a 3 (Group) x 2 (Time: Baseline, Follow-up) mixed ANOVA for each food; measures of intake collected immediately post-intervention were omitted from analyses as these were determined by the intervention protocol. Where the hypothesized Group x Time interactions were found, we explored changes over time within each group using 1way ANOVA and compared the size of changes (from baseline to post-intervention and/or from baseline to follow-up) between groups using pairwise contrasts. Where the mixed ANOVA found main effects but no interactions, main effects contrasts were used to establish the locus of effects. Where Mauchly's test revealed a violation of the assumption of sphericity, Huynh-Feldt or Greenhouse-Geisser correction was applied to the degrees of freedom, as appropriate. Partial etasquared $(\eta 2)$ is reported as an index of effect size; we follow standard practice in interpreting values of $0.01 / 0.06 / 0.14$ for $\eta 2$ as small/ medium/ large effects, respectively (Cohen, 1988).

Additional analyses conducted include the following: (1) Preliminary analyses to check for group differences on baseline measures and in parents' adherence to the taste-exposure protocol, using univariate ANOVA and chi-square tests. (2) Univariate ANOVA and Pearson's correlations to identify other predictors of intervention outcomes. Factors explored include the demographic and 
background measures listed in Table 1, and the numbers of tastes offered and experienced during taste exposure (see Table 2). Outcome measures were changes in liking and consumption (from baseline to post-intervention and/or follow-up). Relationships with outcome measures were examined both among participants overall and among individual groups; alpha was not corrected at this stage, to ensure that no potential predictor was excluded. (3) Stepwise linear regressions to explore whether identified predictor variables moderated the effects of prior visual familiarization on outcome measures. All variables correlated with each outcome were entered into regressions on the relevant measure, along with the factor Group, and interactions were tested between Group and each factor in the final regression model. (4) Mixed 3 (Group) x 3 (Time) ANOVAs were used to explore the impact of the intervention on children's total fruit and vegetable intake and on their attitudes towards foods in general, to identify any effects beyond the targeted foods.

Analyses included all participants for whom questionnaires were returned at post-intervention and/or follow-up, as appropriate to the analysis. Children whose target foods were unfamiliar, rather than disliked (see Methods), were excluded from analyses of changes in liking of that food, due to the lack of a baseline measure of liking. For all other measures, parallel analyses were run including all children, and only those whose target foods were disliked. As the pattern of results was identical, we report results for all participants. Although questionnaire data are ordinal, our data largely met criteria for parametric analysis in other respects (independence, homogeneity of variance, normal distribution); we therefore used parametric analyses, in line with previous similar studies (e.g. Wardle et al., 2003a; 2003b). For measures that were non-normally distributed, nonparametric analyses were also conducted; in all cases, results were in line with the tests reported.

\section{Results}

Preliminary Analyses: Checks for Group Differences

Table 1 presents the demographic and other background measures collected at baseline. There were no significant differences between groups on any measure (all $p \mathrm{~s}>.08$ ). There were also no group differences at baseline in children's liking of their target foods (target fruit: $F(2,103)=1.77$, 
$p=.18$; target vegetable: $F(2,105)=.82, p=.45)$ or intake of these (target fruit: $F(2,123)=2.51, p$ $=.09$; target vegetable: $F(2,124)=.77, p=.47$ ) at baseline (for means, see Table 3 ).

$<$ Table $1>$

During the taste-exposure phase, parents provided a mean of $13.0(\mathrm{SD}=1.97)$ exposures to the target fruit and $12.3(\mathrm{SD}=2.32$ ) exposures to the target vegetable, indicating a high level of adherence to instructions. Children tasted their target fruit a mean of 7.94 times $(\mathrm{SD}=4.98)$ and their target vegetable a mean of 6.91 times $(\mathrm{SD}=4.52)$. There were no differences between groups in the numbers of exposures provided or tastes experienced (see Table 2).

$<$ Table $2>$

Tests of Primary Hypotheses: Effects of Visual Familiarization

\section{Liking of Target Foods}

Table 3 presents parents' ratings of children's liking of the target foods at each time point. At baseline, target foods were rated between 'strongly disliked' and 'disliked' (scores of $1 \& 2$, respectively, on the 5-point scale). More neutral ratings (closer to a score of 3) were given for both foods immediately post-intervention and at follow-up.

\section{< Table 3 >}

$3 \times 3$ mixed ANOVAs were conducted to explore changes in reported liking of each target food. As shown in Figure 2, the three groups showed a very similar profile in their liking of the target fruit. There was a significant main effect of Time, $F(1.34,82.76)=47.87, p<.001, \eta p^{2}=.44$, no main effect of Group, $F(2,62)=.31, p=.73, \eta p^{2}=.01$, and no Group x Time interaction, $F(2.67$, $82.76)=.30, p=.80, \eta \mathrm{p}^{2}=.01$. Main effects contrasts indicated that liking of the fruit increased from baseline to post-intervention, $F(1,62)=52.17, p<.001, \eta p^{2}=.46$, and remained above 
baseline at follow-up, $F(1,62)=54.23, p<.001, \eta p^{2}=.47$, with no change between the latter two time points, $F(1,62)=.29, p=.59, \eta p^{2}=.005$. Liking of the target fruit therefore increased similarly in each group as a result of taste exposure, with no effect of prior visual familiarization.

\section{$<$ Figure $2>$}

The analysis of liking of the target vegetable similarly revealed a main effect of Time, $F(1.65$, $103.93)=39.83, p<.001, \eta p^{2}=.39$, but also a main effect of Group, $F(2,63)=3.21, p=.047, \eta p^{2}$ $=.09$, and a Group $x$ Time interaction, $F(3.30,103.93)=4.42, p=.004, \eta p^{2}=.12$. As expected, all three groups showed large increases in liking of the vegetable as a result of the intervention $\left(\right.$ Vegetable Book: $F(1.50,33.08)=28.06, p<.001, \eta p^{2}=.56$; Fruit Book: $F(2,36)=6.13, p=$ $.005, \eta p^{2}=.25$; Control: $F(1.52,35.03)=10.50, p=.001, \eta p^{2}=.31$. However, as seen in Figure 2, children who looked at a vegetable book showed the largest increases in liking. Planned contrasts confirmed that the Vegetable Book group showed significantly larger increases in liking of the vegetable than other groups both immediately post-intervention (Vegetable Book vs. Controls: $t$ $(87)=4.01, p<.001$; Vegetable Book vs. Fruit Book: $t(87)=4.47, p<.001)$ and at follow-up (Vegetable Book vs. Controls: $t(64)=2.31, p=.024$; Vegetable Book vs. Fruit Book: $t(64)=$ $2.43, p=.018)$. Thus, visual familiarization increased children's liking of the target vegetable over and above the effects of taste exposure, both immediately post-intervention and three months later.

\section{Consumption of Target Foods}

Table 3 displays the mean daily intake of each food reported for children in each condition.

Children consumed target foods regularly during the taste-exposure phase, as directed, but only rarely at baseline and follow-up, when parents could choose whether to make the foods available.

$3 \times 2$ ANOVAs were used to explore changes in consumption of the target foods from baseline to follow-up. The analysis exploring intake of the target fruit found no main effects of Time, $F(1,74)$ $=.94, p=.34, \eta \mathrm{p}^{2}=.01$, Group, $F(2,74)=.86, p=.43, \eta \mathrm{p}^{2}=.02$, and no Group $\mathrm{x}$ Time 
interaction, $F(2,74)=1.37, p=.26, \eta p^{2}=.04$. There were, therefore, no long-term effects of either taste exposure or visual familiarization on children's consumption of their target fruit.

In contrast, group differences were seen in children's consumption of the target vegetable from baseline to follow-up. There was a main effect of Time, $F(1,75)=8.93, p=.004, \eta p^{2}=.11$, no main effect of Group, $F(2,75)=1.13, p=.33, \eta \mathrm{p}^{2}=.03$, and a Group x Time interaction, $F(2,75)$ $=4.13, p=.02, \eta \mathrm{p}^{2}=.10$. Only the Vegetable Book group showed a significant increase in intake of the target vegetable (Vegetable Book: $F(1,26)=14.03, p=.001, \eta p^{2}=.35$; Fruit Book: $F(1,21$ ) $=3.47, p=.08, \eta p^{2}=.14$; Control: $\left.F(1,28)=.02, p=.89, \eta p^{2}=.001\right)($ see Figure 3$)$. Planned contrasts confirmed that the Vegetable Book group showed a larger increase in vegetable intake than children in the Control group, $t(75)=2.79, p=.007$, while the difference between the Vegetable and Fruit Book groups bordered on significance, $\mathrm{t}(75)=1.95, \mathrm{p}=.055$. Thus, looking at vegetable books with children prior to offering them repeated tastes of the food increased intake of the vegetable three months later, compared to children who did not see such books.

\section{$<$ Figure $3>$}

\section{Other Predictors of Intervention Success}

Next, we explored whether other measures were related to the intervention outcomes and, if so, whether these moderated the effects of prior visual familiarization. Based on the results of the primary analyses reported above, we specified three outcome measures of interest: changes in liking of the target vegetable from baseline to post-intervention, and from baseline to follow-up, and change in consumption of the target vegetable from baseline to follow-up.

The only background measure to correlate with outcome measures among children overall was Frequency of Family Meals, which was positively related to change in liking of the vegetable (post-intervention), $r(83)=.25, p=.023$ (all other $p s>.05$ ). When the three groups were examined separately, change in liking (post-intervention) was related to family purchases of fruit in the 
Control group, $r(29)=.46, p=.013$, and to baseline Child Food Neophobia Scale scores in the Vegetable Book group, $r(31)=-.43, p=.016$. Change in consumption (follow-up) was related to baseline Food Fussiness in the Control group, $r(29)=.40, p=.031$.

Among the measures collected during taste exposure, the number of times the target vegetable was offered was not related to any outcome measure, for children overall or for any group (all $p \mathrm{~s}>.05$ ). However, the number of times children tasted the vegetable was related to changes in liking both post-intervention, $r(85)=.57, p<.001$, and at follow-up, $r(64)=.50, p<.001$. This relationship was seen in each individual group post-intervention (Fruit Book: $r(28)=.61, p<.001$; Vegetable Book: $r(29)=.73, p<.001$; Control: $r(28)=.38, p<.048)$, but only among experimental groups at follow-up (Fruit Book: $r(19)=.49, p=.031$; Vegetable Book: $r(22)=.66, p=.001$; Control: $r(23$ ) $=.25, p=.25$ ). The number of times the vegetable was tasted was related to change in vegetable consumption (follow-up) only among the Fruit Book group, $r(21)=.44, p=.047$ (other $p \mathrm{~s}>.05$ ).

Stepwise linear regression was used to explore the relative contributions of the identified correlates of each outcome measure and whether these moderated the effects of Group. Change in liking of the target vegetable (post-intervention) was entered into a regression with Frequency of Family Meals, family purchases of fruit, Child Food Neophobia Scale scores, Number of tastes, and Group as predictors. The final model accounted for $54 \%$ of the variance in change in liking, with significant contributions from Number of tastes, Frequency of Family Meals and Group (see Table 4). There were no significant interactions between Group and other predictors ( $p s>.18$ ). Change in liking of the target vegetable (follow-up) was entered into a similar regression with Number of tastes and Group as predictors. Both predictors were retained in the final model, which accounted for $28 \%$ of the variance in change in liking (see Table 5). There was no interaction between the factors ( $p>.1$ ). Finally, change in consumption of the vegetable (follow-up) was entered into a regression model with Food Fussiness, Number of tastes, and Group as predictors. Only Group was retained in the final model; this accounted for $12 \%$ of the variance in intake of the vegetable (see Table 6). Thus, the impact of picture books on liking and consumption of the target vegetable was not moderated by other predictors of the intervention's outcomes. 
$<$ Tables 4,5 and $6>$

Impact of Intervention on Children's Broader Attitudes towards Food

Finally, we explored whether the intervention influenced children's overall intake of fruit and vegetables or their attitudes towards trying new foods in general.

\section{Total Fruit and Vegetable Intake}

The mean total daily intake of fruit and vegetables by children in each group is shown in Table 7 . 3 (Group) x 3 (Time) mixed ANOVAs were used to explore changes in total fruit and vegetable intake over the course of the intervention. The analysis of total fruit intake revealed a main effect of Time, $F(2,132)=5.08, p=.008, \eta p^{2}=.07$, reflecting a decline in intake from baseline to follow-up, $F(1,66)=9.32, p=.003, \eta p^{2}=.12$. There was no effect of Group, $F(2,66)=.49, p=$ $.61, \eta p^{2}=.02$, or Group $\mathrm{x}$ Time interaction, $F(4,132)=.98, p=.42, \eta p^{2}=.03$. A similar pattern was seen in the analysis of children's total vegetable intake, although the effect of Time did not

reach significance, $F(1.8,126.5)=2.75, p=.073, \eta p^{2}=.04$. Again, there was no effect of Group, $F(2,70)=.37, p=.69, \eta p^{2}=.01$, or Group $x$ Time interaction, $F(3.6,126.5)=.49, p=.72, \eta p^{2}=$ .01. These analyses indicate that visual familiarization to a single food did not increase children's overall intake of the food group, suggesting that effects were specific to targeted vegetables.

$<$ Table $7>$

\section{Children's Attitudes towards New Foods}

Children's Food Neophobia Scale (CFNS) and Food Fussiness (CEBQ:FF) scores at each time point are shown in Table 7.3 (Group) x 3 (Time) mixed ANOVAs were used to explore changes over time in the attitudes indexed by the two scales. The analysis of CFNS scores found no main effects of Time, $F(1.8,129.2)=1.78, p=.18, \eta p^{2}=.02$, or Group, $F(2,73)=.45, p=64, \eta p^{2}=$ .01 , but there was a Group $\mathrm{x}$ Time interaction, $F(3.5,129.2)=.2 .93, p=.023, \eta p^{2}=.07$ (see Figure 4). Children in the Control group showed a trajectory of increasing food neophobia over 
time, $F(2,56)=6.49, p=.003, \eta p^{2}=.19$, with a large significant increase from baseline to followup, $F(1,28)=12.42, p=.001, \eta p^{2}=.31$. In contrast, no changes in neophobia were reported for children in the Vegetable Book, $F(1.6,39.5)=.67, p=.48, \eta p^{2}=.03$, or Fruit Book groups, $F(2,40)=.54, p=.59, \eta p^{2}=.03$. Pairwise contrasts confirmed that children in the Control group showed a significantly larger increase in neophobia from baseline to follow-up than those in the Vegetable Book group, $t(75)=3.26, p=.002$. There were no other group differences $(p s>.1)$.

\section{$<$ Figure $4>$}

A similar pattern was seen in children's Food Fussiness (CEBQ:FF) scores. There were no main effects of Time, $F(1.8,132.2)=1.35, p=.26, \eta p^{2}=.02$, or Group, $F(2,73)=.70, p=.50, \eta p^{2}=$ .02 , but there was a significant interaction, $F(3.6,132.2)=2.59, p=.045, \eta p^{2}=.07$ (see Figure 4). Again, children in the Control group showed a marked increase in food fussiness over time, $F(2,56)=.4 .94, p=.011, \eta p^{2}=.15$, with large increases from baseline to post-intervention, $F(1$, $28)=6.48, p=.017, \eta p^{2}=.19$, and from baseline to follow-up, $F(1,28)=8.15, p=.008, \eta p^{2}=$ .23. Children in the Vegetable Book group, $F(2,50)=.81, p=.45, \eta p^{2}=.03$, and Fruit Book group, $F(2,40)=2.22, p=.12, \eta p^{2}=.10$, showed no changes in food fussiness over time. Pairwise contrasts revealed that the Vegetable Book group showed smaller increases in food fussiness from baseline to post-intervention than both the Control group, $\mathrm{t}(101)=2.91, \mathrm{p}=.004$, and Fruit Book group, $\mathrm{t}(101)=2.77, \mathrm{p}=.007$. At follow-up, the difference between the Vegetable Book and Control group remained significant, $t(75)=2.76, p=.007$. Thus, the increases in food neophobia and food fussiness over the course of the study that were characteristic of control children were not shown by children who saw picture books, particularly those who saw books about vegetables.

\section{Discussion}

Previous studies have shown that familiarization to foods through picture books increases children's willingness to taste unfamiliar foods and their liking and consumption of these in laboratory tests (Heath et al., 2014; Houston-Price et al., 2009b). This study adds to this literature 
in demonstrating that looking at picture books about vegetables immediately before children are offered repeated tastes of these at home enhances their liking and intake of vegetables relative to children receiving taste exposure alone, with effects lasting several months.

A wealth of previous research has shown that repeated taste exposure enhances children's liking and consumption of exposed foods (Caton et al., 2013; Fildes et al., 2013; Maier et al., 2007; Remington et al., 2012; Wardle et al., 2003a, 2003b). In this study, too, liking of the target foods was reported to increase after two weeks of daily taste exposure, and this change in liking was maintained for several months afterwards. However, the current study further demonstrates the supplementary benefits of familiarizing children with vegetables through picture books prior to offering them at mealtimes. According to parents' reports, looking at books about vegetables enhanced children's liking of the target vegetable during the taste-exposure phase and for at least three months afterwards. Intake of the target vegetable was also greater at the later time point among children who had seen a book about this food. Thus, according to parental reports, two weeks of looking at a picture book about a disliked or unfamiliar vegetable boosts children's liking and consumption of the food over and above the impact of repeated taste exposure.

Further analyses investigated which demographic and background measures predicted the success of the intervention, along with the role played by the number of tastes offered and accepted during the taste-exposure phase, and how these influenced the effects of visual familiarization. Changes in liking and intake of targeted vegetables were related to the number of times children tasted the vegetable during the taste-exposure phase; this finding aligns with previous reports of acceptance being a function of the frequency of taste exposure (e.g. Birch \& Marlin, 1982; Caton, et al., 2013; Wardle et al., 2003b). Changes in liking and intake were also related to the frequency with which families engaged in shared mealtimes, and by children's attitudes towards foods at baseline. However, none of these factors moderated the effects of visual familiarization. These findings indicate that looking at vegetable books supports increases in liking and consumption of the targeted food regardless of other individual, family or demographic influences on children's food preferences. All parents, including those with children considered 'fussy eaters', can therefore be encouraged to use picture books as a support when introducing vegetables into their child's diet. 
Books about fruits did not show the same benefits in this study. Taste exposure increased reported liking of fruits (but, surprisingly, not intake of fruits) among all children, regardless of whether they had received a book about the fruit. The different findings for the two food groups are most plausibly explained in terms of children's natural preference for sweet foods and dislike of bitter tastes (Wardle \& Cooke, 2008; Reed \& Knaapila, 2010; Ventura \& Mennella, 2011). By alerting children to the sweet taste of the fruit, taste exposure appears to have been sufficient to increase liking of this food type, with little scope for further facilitation by picture books. In contrast, more bitter-tasting vegetables may have been more resistant to acceptance, allowing efforts to introduce these foods to benefit from the extra 'push' provided by visual familiarization.

Analyses of children's total fruit and vegetable intake confirmed that the effects of the intervention were specific to targeted foods. In fact, total fruit and vegetable intake tended to decline during the six month period of the study. In contrast to Sullivan and Birch (1990), we did not find this decline to be linked to increased consumption of target foods, suggesting that it is more likely to reflect natural changes in children's diets at the end of the second year, a typical time for the onset of more restricted eating behavior. This hypothesis is supported by the increasing levels of food neophobia and food fussiness reported by parents of children in the control group during the study. Russell and Worsley (2008) found that food neophobia was associated with low levels of liking of all food groups, including vegetables, and with reduced variety in the range of foods consumed. It is perhaps not surprising, then, that children's total fruit and vegetable consumption were in decline during the intervention period.

Strikingly, however, looking at picture books appears to have disrupted the increases in food neophobia and food fussiness that are characteristic of children around their second birthday. While the control group showed a typical profile of increasingly negative attitudes towards new foods, children in the familiarization groups did not. The strongest effects were, again, seen for those who had looked at vegetable books. These unexpected findings add to our understanding of the potential benefits of picture books, indicating that these may extend beyond enhancing liking and consumption of targeted foods. Although looking at picture books did not lead to greater 
intake of fruit and vegetables overall, future work should investigate other potential consequences of the observed lower levels of food fussiness and neophobia, such as increased dietary variety.

It is important to acknowledge that the positive findings of this study rely on parental reports, rather than objective measures of intake. While previous studies have demonstrated effects of visual familiarity on measures of preference and consumption collected by researchers in laboratory settings (Heath et al., 2014; Houston-Price et al., 2009a, 2009b), the current study set out to investigate the impact of picture books in the home environment. Parents were asked to report on the intervention outcomes, in order to establish whether the picture books helped them to introduce the foods they wanted their child to eat. Parents were also, necessarily, the agents of the intervention - they shared the books with their children and provided repeated taste exposures to the target foods afterwards - so they could not be blind to experimental condition. Involving parents in these ways, while crucial to our objectives, opens the window for social desirability biases in the reporting of children's liking and consumption of the target foods (Hebert, Clemow, Pbert, Ockene \& Ockene, 1995; Kristal, Beresford \& Lazovich, 1994).

There are good reasons to be trusting of parents' reports, however. Other researchers have found strong correlations between mothers' reports of children's food preferences and children's own reports (Galloway, Lee \& Birch, 2003). The findings of this study also corroborate those of previous work using more objective measures (Heath et al., 2014; Houston-Price et al., 2009a, 2009b). Most important to consider, however, is the control inherent in the design of the study (which involved random allocation to groups), in combination with the consistency and specificity of the positive outcomes reported (familiarity effects were seen only for vegetables, and only among children who saw a vegetable book, for every outcome measure). These factors mitigate very strongly against the presence of social desirability effects in parents' reports. If social desirability effects were driving their responses, all three groups would be expected to report positive outcomes. In contrast, parents who received books about fruits failed to report any positive changes in liking or intake of fruits, parents in all groups reported decreases in total fruit consumption over the course of the study, and parents in the control group reported increasingly negative attitudes towards new foods among their children. Parents were therefore not unwilling to 
say when the intervention did not work. The consistent and specific reporting of positive effects on children's liking and consumption of vegetables only among those who were exposed to books about vegetables is unlikely, therefore, to be attributable to social desirability.

The study does, nevertheless, leave unanswered the important question of how pictures books exert their positive effects. Increased familiarity with the targeted food is likely to be the key factor, given the well-documented link between stimulus familiarity and positive attitudes (e.g., Butler \& Berry, 2004; Zajonc, 1968; 2001). However, the type of familiarization provided by the books used in this study cannot be described as 'mere exposure' (Zajonc, 1968); the 'farm to fork' format of each book also provided information about the food's origins, how it can be prepared, and the foods it might be combined with, as well as its appearance, inside and out. The books are, therefore, likely to increase the food's conceptual familiarity, as well as its perceptual familiarity.

Little is known about how children develop their conceptual understanding of the food domain (see Mura Paroche, Caton, Vereijken, Weenen \& Houston-Price, 2017, for a review), although work by Nguyen and colleagues has shown that the ability to organize foods into taxonomic, thematic, script and evaluative categories is already quite sophisticated by the late preschool years (Nguyen, 2007a, b, 2008; Nguyen \& Murphy, 2003). This type of knowledge may prove to be important in the development of food preferences. Gripshover and Markman (2013) used story books to educate 4- to 5-year-olds about nutritional concepts such as food categories, the importance of dietary variety, and how nutrients support body functions. Interestingly, in addition to enhancing children's understanding of foods' nutritional properties, the intervention also boosted their intake of vegetables at snack time; much of the variance in intake was explained by changes in conceptual knowledge. Osborne and Forestell (2012) found similar positive effects of exposure to books about healthy eating and pictures of fruits and vegetables on 4- to 8-year-olds' fruit intake. However, both Gripshover and Markman's (2013) and Osborne and Forestell's (2012) studies exposed children to color pictures of foods, as well as information about healthy eating, leaving open the possibility that increased visual familiarity may have played a role in the outcomes of these studies. 
No study to date has directly compared the effects of exposure to pictures versus information about foods as a means of testing the importance of perceptual versus conceptual familiarity with foods. Houston-Price et al. (2009a) compared the effects of books containing only pictures with books containing both pictures and information about foods (similar those used in the current study) on 2-year-olds' visual preferences for exposed foods; although no significant difference was seen between conditions, results were more robust when both pictures and information were provided. More recently, Rioux, Lafraire and Picard (2018) found that exposure to pictures of vegetables on placemats increased preschool children's intake of both targeted and non-targeted vegetables. Although this finding might appear to suggest that visual familiarity was the active ingredient in their manipulation, Rioux et al. also assessed children's ability to categorize foods; this measure moderated the impact of exposure on intake, highlighting the importance of children's conceptual knowledge. In combination, this work suggests that knowing about foods may be as important (or more important) than knowing what foods look like. The extent to which liking and intake of a food are driven by familiarity with a food's visual appearance versus increased conceptual knowledge about the food is clearly a question for further research. Studies exploring the relative influence of pictures versus information on younger and older preschoolers' food liking and intake would be especially beneficial in elucidating how food familiarization exerts its effects on children of different ages.

Alongside these characteristics of the books themselves, the way in which parents and children engage with them may also play a role in their effects. We invited parents to engage with books however they chose, either reading the text provided, talking about foods using their own words, or both. Although we did not ask parents to record how they read the books, individual differences are typically found in the extent to which parents elaborate while reading stories; reading style also varies with the type of material (e.g. Haden, Reese \& Fivush, 1996). Such work shows that elaboration and questioning during shared book-reading often support children's language skills, but less is known about how the nature of the experience supports development in other domains (see Walsh \& Hodge, 2016, for a review). Interestingly, DeDroog et al. (2014) found that listening to stories about characters who eat vegetable snacks led to greater intake of carrots among 4- to 6year-old children when the reader asked children questions during the story session. Further work 
is needed to ascertain whether parents should be encouraged to use questions and elaborate on the content when looking at picture books about vegetables with toddlers.

Future work might also explore whether parents' attitudes or behaviors towards foods are influenced by engaging in shared book reading. If so, this raises the possibility that books' effects on children might be mediated by their effects on parents. A number of mechanisms could support such an indirect influence. For example, if parents become more positive towards a food as a result of reading a book about it, they might be more motivated to offer children tastes of the food, or become more sensitive to changes in children's behaviors towards the food, leading to reports of more positive outcomes. Longer-term effects of the books might be driven by greater availability of foods that are better liked ( $\&$ more frequently purchased) by parents, or by more frequent modelling of eating the food by parents, both factors known to influence children's eating behavior (Ventura \& Birch, 2008). We found no evidence of such indirect influences in the data reported here; for example, there were no between-group differences in the number of taste exposures parents provided, or in parents' purchases of the target foods, and neither of these factors predicted the intervention outcomes. However, it remains a possibility that parents' attitudes or behaviors towards target foods changed as a result of reading the picture books, and that this supported changes in their children.

A related issue is the nature of the relationship between the effects of visual familiarization and taste exposure, and whether this is additive or interactive. Given that both visual familiarity and taste exposure have been shown to independently influence food acceptance, the positive effects reported in this study may simply reflect the additive benefits of receiving both types of exposure, one after the other. Alternatively, prior visual familiarity might influence the nature of the taste exposure phase itself, perhaps enhancing its effectiveness by changing how children (and/or parents) approach the tasting regime. Although the data reported in this manuscript do not tease apart these possibilities, the diary measures provided by parents during the taste exposure phase do speak to this question (see Houston-Price et al., under review). Compared to controls, children who had seen vegetable picture books showed greater willingness to taste, liking and intake of the vegetable during the taste exposure phase, while their parents found it easier and more enjoyable 
to engage in tasting sessions involving the target vegetable. These findings suggest that families' experiences of taste exposure were directly affected by engaging in shared book reading. Further work is clearly needed to establish how food familiarity supports such positive influences. A better understanding of the mechanism(s) that underlie the effects of picture books would help in optimizing their potential to bring about long-term changes in children's diets.

In conclusion, this study confirms the benefits of familiarizing young children to vegetables through picture books immediately before they are offered repeated tastes of the food. Despite toddlerhood being a challenging age at which to introduce new foods, parents who looked at vegetable books with their 2-year-olds before offering them repeated tastes of the food at mealtimes reported enhanced liking and consumption of the targeted foods, lasting for several months. Lifelong eating patterns are established at an early age, and the link between fruit and vegetable consumption in early childhood and healthy eating in later life is well-documented (e.g., Maynard, et al., 2003). To the extent that picture books help to bring children's fruit and vegetable intake closer to the recommended five portions a day (NHS, 2003, 2011), they could be an important contributor to health and longevity.

\section{References}

Addessi, E., Galloway, A. T., Visalberghi, E., \& Birch, L. (2005). Specific social influences on the acceptance of novel foods in 2-5-year-old children. Appetite, 45, 264-271.

Ashcroft, J., Semmler, C., Carnell, S., van Jaarsveld, C. H., \& Wardle, J. (2008). Continuity and stability of eating behaviour traits in children. European Journal of Clinical Nutrition, 62, 985-990.

Beck, T. K., Nicklaus, S., Jensen, S., Issanchou, S., \& Kidmose, U. (2013). Comparisons of individual bitterness perception and vegetable liking and consumption among Danish consumers: A pilot study for a cross-cultural sensory study between Denmark and France. MENU: Journal of Food \& Hospitality Research, 2, 7-14.

Birch, L. L., \& Marlin, D. W. (1982). I don't like it; I never tried it: Effects of exposure on two-year-old children's food preferences. Appetite: Journal for Intake Research, 3, 353- 
360.

Birch, L. L., McPhee, L., Shoba, B. C., Pirok, E., \& Steinberg, L. (1987). What kind of exposure reduces children's food neophobia? Looking vs. tasting. Appetite, 9, 171-178.

Borzekowski, D. L. G., \& Robinson, T. N. (2001). The 30-second effect: an experiment revealing the impact of television commercials on food preferences of preschoolers. Journal of the American Dietetic Association, 101, 42-46.

Bristol Online Surveys, IT Services R\&D/ ILRT, University of Bristol, Bristol, UK, from http://www.survey.bris.ac.uk

Buijzen, M., Schuurman, J., \& Bomhof, E. (2008). Associations between children's television advertising exposure and their food consumption patterns: A household diary-survey study. Appetite, 50, 231-239.

Busick, D. B., Brooks, J., Pernecky, S., Dawson, R., \& Petzoldt, J. (2008). Parent food purchases as a measure of exposure and preschool-aged children's willingness to identify and taste fruit and vegetables. Appetite, 51, 468-473.

Butler, L. T., \& Berry, D. C. (2004). Understanding the relationship between repetition priming and mere exposure. British Journal of Psychology, 95, 467-487.

Carruth, B. R., \& Skinner, J. D. (2000). Revisiting the picky eater phenomenon: Neophobic behaviors of young children. Journal of the American College of Nutrition, 19, 6, 771780.

Carruth, B. R., Ziegler, P. J., Gordon, A., \& Barr, S. I. (2004). Prevalence of picky eaters among infants and toddlers and their caregivers' decisions about offering a new food. Journal of the American Dietetic Association, 104, 57-64.

Cashdan, E. (1994). A sensitive period for learning about food. Human Nature, 5, 279-291.

Cashdan, E. (1998). Adaptiveness of food learning and food aversions in children. Social Science Information, 37, 613-632.

Caton, S.J., Ahern, S.M., Remy, E., Nicklaus, S., Blundell, P. \& Hetherington, M.M. (2013). Repetition counts: Repeated exposure increases intake of a novel vegetable in UK pres-school children compared to flavour-flavour and flavour-nutrient learning. British Journal of Nutrition, 109 (11), 2089-2097. 
Cohen, J. (1988). Statistical power analysis for the behavioral sciences (2nd ed.).Hillsdale, NJ: Erlbaum.

Cooke, L. (2007). The importance of exposure for healthy eating in childhood: A review. Journal of Human Nutrition \& Dietetics, 20, 294-301.

Cooke, L., Wardle, J., \& Gibson, E. L. (2003). Relationship between parental report of food neophobia and everyday food consumption in 2-6-year-old children. Appetite, 41, 205206.

Cooke, L., Wardle, J., Gibson, E., Sapochnik, M., Sheiham,, A. \& Lawson, M. (2004). Demographic, familial and trait predictors of fruit and vegetable consumption by preschool children. Public Health Nutrition, 7, 295-302.

Dazeley, P. \& Houston-Price, C. (2014). Exposure to foods' non-taste sensory properties: A nursery intervention to increase children's willingness to try fruit and vegetables. Appetite, 84, $1-6$.

Dazeley, P., Houston-Price, C. \& Hill, C.E. (2012). Should healthy eating programmes incorporate interaction with foods in different sensory modalities? A review of the evidence. British Journal of Nutrition, 108, 769-777.

De Droog, S.M., Buijzen, M. \& Valkenburg, P.M. (2014). Enhancing children's vegetable consumption using vegetable-promoting picture books: The impact of interactive shared reading and character-product congruence. Appetite, 73, 73-80.

Department of Health, Social Sciences \& Public Safety (2011). Healthy start. Accessed on 25 October, 2017 at www.healthystart.nhs.uk.

Devine, C., Connors, M., Bisogni, C., \& Sobal, J. (1998). Life-course influences on fruit and vegetable trajectories: Qualitative analysis of food choices. Journal of Nutrition Education \& Behavior, 30, 361-370.

de Wild, V.W.T., de Graaf, C., \& Jager, G. (2013). Effectiveness of flavour nutrient learning and mere exposure as mechanisms to increase toddler's intake and preference for green vegetables. Appetite, 64, 89-96.

Domel, S. B., Thompson, W. O., Davis, H. C., Baranowski, T., Leonard, S. B., \& Baranowski, J. (1996). Psychosocial predictors of fruit and vegetable consumption among elementary school children. Health Education Research, 11, 299-308. 
Fildes, A., van Jaarsveld, C.H.M., Wardle, J. \& Cooke, L. (2013). Parent-administered exposure to increase children's vegetable acceptance: A randomized controlled trials. Journal of the Academy of Nutrition \& Dietetics, 114 (5), 881-888.

First Steps Nutrition Trust (2017). Eating well: The first year. A guide to introducing solids and eating well up to baby's first birthday. Retrieved on 25 October, 2017, from www.firststepsnutrition.org.

Fox, M.K., Condon, E., Briefel, R.R., Reidy, K.C. \& Deming, D.M. (2010). Food consumption patterns of young pre-schoolers: Are they starting off on the right path? Journal of the American Dietetic Association, 110 (12, Supplement), S52-59.

Galloway, A. T., Lee, Y., \& Birch, L. L. (2003). Predictors and consequences of food neophobia and pickiness in young girls. Journal of the American Dietetic Association, 103, 692-698.

Gibson, E. L., Wardle, J., \& Watts, C. (1998). Fruit and vegetable consumption, nutritional knowledge and beliefs in mothers and children. Appetite, 31, 205-228.

Gripshover, S.J. \& Markman, E.M. (2013). Teaching young children a theory of nutrition: Conceptual change and the potential for increased vegetable consumption. Psychological Science, 24 (8), 1541-1553.

Haden, C.A., Reese, E. \& Fivush, R. (1996). Mothers' extratextual comments during storybook reading: Stylistic differences over time and across texts. Discourse Processes, 21, 135-169.

Hausner, H., Olsen, A. \& Moller, P. (2012). Mere exposure and flavour-flavour learning increase 2-3 year-old children's acceptance of a novel vegetable. Appetite, 58 (3), 1152-1159.

Heath, P. M., Houston-Price, C. \& Kennedy, O. B. (2010). Can visual exposure impact on children's visual preferences for fruit and vegetables? Proceedings of the Nutrition Society, 69 (OCE6), E422.

Heath, P., Houston-Price, C. \& Kennedy, O.B. (2011). Increasing food familiarity without the tears: A role for visual exposure? Appetite, 57, 832-838.

Heath, P., Houston-Price, C. \& Kennedy, O.B. (2014). Let's look at leeks! Picture books increase toddlers' willingness to look at, taste and consume unfamiliar vegetables. Frontiers in Psychology, 5 (191), 1-11.

Hebert, J. R., Clemow, L., Pbert, L., Ockene, I. S., \& Ockene, J. K. (1995). Social desirability 
bias in dietary self-report may compromise the validity of dietary intake measures. International Journal of Epidemiology, 24, 389-398.

Hetherington, M. M., \& Rolls, B. J. (1996). Sensory-specific satiety: theoretical framework and central characteristics. In E. D. Capaldi (Ed.), Why we eat what we want: The psychology of eating (pp. 267-290). Washington, DC: American Psychological Association.

Horst, J.S. \& Houston-Price, C. (2015). Editorial: An open book: What and how children learn from picture and story books. Frontiers in Psychology, 6, 1719, doi: 10.3389/fpsyg.2015.01719.

Houston-Price, C., Burton, E., Hickinson, R., Inett, J., Moore, E., Salmon, K., \& Shiba P. (2009a). Picture book exposure elicits positive visual preferences in toddlers. Journal of Experimental Child Psychology, 104, 89-104.

Houston-Price, C., Butler, L., \& Shiba, P. (2009b). Visual exposure impacts on toddlers' willingness to taste fruit and vegetables. Appetite, 53, 450-453.

Houston-Price, C., Owen, L. H., Kennedy, P. B., \& Hill, C. (under review) Parents' experiences of introducing toddlers to fruits and vegetables through repeated exposure, with and without prior visual familiarization to foods: Evidence from daily diaries.

Kalat, J., \& Rozin, P. (1973). "Learned safety” as a mechanism in long-delay taste-aversion learning in rats. Journal of Comparative \& Physiological Psychology, 83, 198-207.

Keller, K.L. (2014). The use of repeated exposure and associative conditioning to increase vegetable acceptance in children: Explaining the variability across studies. Journal of the Academy of Nutrition and Dietetics, 114 (8), 1169-1173.

Kristal, A. R., Beresford, S. A., \& Lazovich, D. (1994). Assessing change in diet-intervention research. The American Journal of Clinical Nutrition, 59, 1855-1895.

Lakkakula, A., Geaghan, J., Zanovec, M., Pearce, S. \& Tuuri, G. (2010). Repeated taste exposure increases liking for vegetables by low-income elementary school children. Appetite, 55, 226231.

Livingstone, K., M. (2010, April). Visual Exposure using Picture Books Improves Children's Preferences for Fruits and is Affected by Neophobia Status and Parental Influences (BSc Project). University of Reading. 
Lowe, C. F., Horne, P. J., Tapper, K., Bowdery, M., \& Egerton, C. (2004). Effects of a peer modelling and rewards-based intervention to increase fruit and vegetable consumption in children. European Journal of Clinical Nutrition, 58, 510-522.

Maier, A., Chabanet, C., Svhaal, B., Issanchou, S., \& Leatherwood, P. (2007). Effects of repeated exposure on acceptance of initially disliked vegetables on 7-month old infants. Food Quality and Preference, 18, 1023-1032.

Mura Paroche, M., Caton, S.J., Vereijken, C.M.J.L., Weenen, H. \& Houston-Price, C. (2017). How infants and young children learn about food: A systematic review. Frontiers in Psychology, doi: 10.3389/fpsyg.2017.01046.

Maynard, M., Gunnell, D., Emmett, P., Frankel, S., \& Davey Smith, G. (2003). Fruit, vegetables, and antioxidants in childhood and risk of adult cancer: The Boyd Orr cohort. Journal of Epidemiology and Community Health, 57, 218-225.

National Diet and Nutrition Survey (2014). NDNS: Results from years 1 to 4 combined of the rolling programme for 2008 and 2009 to 2011 and 2012: Report. Public Health England. Retrieved October 24, 2017, from www.gov.uk/government/publications.

Nguyen, S. P. (2007a). Cross-classification and category representation in children's concepts. Developmental Psychology, 43(3), 719-731.

Nguyen, S. P. (2007b). An apple a day keeps the doctor away: Children's evaluative categories of food. Appetite, 48(1), 114-118

Nguyen, S. P. (2008). Children's evaluative categories and inductive inferences within the domain of food. Infant \& Child Development, 17(3), 285-299.

Nguyen, S. P., \& Murphy, G. L. (2003). An apple is more than just a fruit: cross-classification in children's concepts. Child Development, 74(6), 1783-1806.

NHS (2003). 5 a day. Accessed on 25 October, 2017 at www.nhs.uk/livewell/5aday/.

NHS (2011). 5 a day portion sizes. Retrieved January 8, 2012, from http://www.nhs.uk/Livewell/5ADAY/Pages/Portionsizes.aspx

Nicklaus, S., Boggio, V., Chabanet, C., \& Issanchou, S. (2005). A prospective study of food variety seeking in childhood, adolescence and early adult life. Appetite, 44, 289-297.

Nicklaus, S. (2011). Children's acceptance of new foods at weaning: Role of practices of weaning and of food sensory properties. Appetite, 57 (3), 812-815. 
Osborne, C.L. \& Forestell ,C.A. (2012). Increasing children's consumption of fruit and vegetables: Does the type of exposure matter? Physiology \& Behavior 106(3), 362-368.

Pliner, P. (1994). Development of measures of food neophobia in children. Appetite, 23, 147163.

Pliner, P., \& Hobden, K. (1992). Development of a scale to measure the trait of food neophobia in humans. Appetite, 19, 105-120.

Public Health England (2009). Change 4 life. Accessed 25 October, 2017, at www.nhs.uk/change4life.

Raudenbush, B., \& Frank, R.A. (1999). Assessing food neophobia: The role of stimulus familiarity. Appetite 32, 261-271.

Reed, D.R. \& Knaapila, A. (2010). Genetics of taste and smell: Poisons and pleasures. Progress in Molecular Biology and Translational Science, 94, 213-240.

Remington, A., Anez, E., Croker, H., Wardle, J. \& Cooke, L. (2012). Increasing food acceptance in the home setting: A randomized controlled trial of parent-administered taste exposure with incentives. American Journal of Clinical Nutrition, 95, 72-77.

Remy, E., Issanchou, S., Chabanet, C., Nicklaus, S. (2013). Repeated exposure of infants at complementary feeding to a vegetable puree increases acceptance as effectively as flavourflavor learning and more effectively than flavour-nutrient learning. Journal of Nutrition, 143 (7), 1194-1200.

Rioux, C., Lafraire, J., \& Picard, D. (2018). Visual exposure and categorization performance positively influence 3- to 6-year-old children's willingness to taste unfamiliar vegetables. Appetite, 120, 32-42.

Robinson, T.N., Borzekowski, D.L.G, Matheson, D.M. \& Kraemer, H.C. (2007). Effects of fast food branding on young children's taste preferences. Archives of Pediatrics and Adolescent Medicine, 161 (8), 792-797.

Rozin, P. (1976). The selection of foods by rats, humans and other animals. In J.S. Rosenblatt (Ed.), Advances in the study of behaviour (6th edition). New York: Academic Press.

Russell, C. G., \& Worsley, A. (2008). A population-based study of preschoolers' food neophobia and its associations with food preferences. Journal of Nutrition Education and Behaviour, 40, 11-19. 
Skinner, J. D., Carruth, B.R., Bounds, W., Ziegler, P., \& Reidy, K. (2002). Do food-related experiences in the first 2 years of life predict dietary variety in school-aged children? Journal of Nutrition Education and Behavior, 34, 310-315.

Sullivan, S. A., \& Birch, L. L. (1990). Pass the sugar, pass the salt: Experience dictates preference. Developmental Psychology, 26, 546-551.

Tuorila, H., \& Mustonen, S. (2010). Reluctant trying of an unfamiliar food induces negative affection for the food. Appetite, 43, 418-421.

Ventura, A.K. \& Birch, L.L. (2008). Does parenting affect children's eating and weight status? International Journal of Behavioral Nutrition \& Physical Activity, 5, 15.

Ventura, A.K. \& Mennella, J.A. (2011). Innate and learned preferences for sweet taste during childhood. Current Opinion in Clinical Nutrition and Metabolic Care, 14 (4), 379-384.

Walsh, R.L. \& Hodge, K.A. (2016). Are we asking the right questions? An analysis of research on the effects of teachers' questionning on children's language during shared book reading with children. Journal of Early Childhood Literacy, 1-31.

Wardle, J., \& Cooke, L. (2008). Genetic and environmental determinants of children's food preferences. British Journal of Nutrition, 99 (Suppl. 1), S15-S21.

Wardle, J., Cooke, L., Gibson, E. L., Sapochnik, M., Sheiham, A., \& Lawson, M. (2003a). Increasing children's acceptance of vegetables: A randomized trial of parent-led exposure. Appetite, 40, 155-162.

Wardle, J., Guthrie, C. A., Sanderson, S., \& Rapoport, L. (2001). Development of the children's eating behaviour questionnaire. Journal of Child Psychology and Psychiatry, 42, 963-970.

Wardle, J., Herrera, M. L., Cooke, L., \& Gibson, E. L. (2003b). Modifying children's food preferences: The effects of exposure and reward on acceptance of an unfamiliar vegetable. European Journal of Clinical Nutrition, 57, 341-348.

World Cancer Research Fund (2010). The great grub club: Being healthy is fun! Retrieved 25 October, 2017, from www.greatgrubclub.com.

Worobey, H., Ostapkovich, K., Yudin, K., \& Worobey, J. (2010). Trying versus liking fruits and vegetables: Correspondence between mothers and pre-schoolers. Ecology of Food and Nutrition, 49, 87-97. 
Zajonc, R. B. (1968). Attitudinal effects of mere exposure. Journal of Personality \& Social Psychology, 9, 1-27.

Zajonc, R. B. (2001). Mere exposure: A gateway to the subliminal. Current Directions in Psychological Science, 10, 224-228. 
Appendix I

\section{Fruit and Vegetable Familiarity \& Liking Questionnaire}

Please indicate how much YOUR CHILD likes the vegetable named.

\begin{tabular}{|c|c|c|c|c|c|c|}
\hline & \multicolumn{6}{|c|}{ How much does YOUR CHILD like this vegetable? } \\
\hline & Never Tried & $\begin{array}{c}\text { Strongly } \\
\text { Dislikes }\end{array}$ & Dislikes & $\begin{array}{c}\text { Neither Likes } \\
\text { Nor Dislikes }\end{array}$ & Likes & $\begin{array}{c}\text { Strongly } \\
\text { Likes }\end{array}$ \\
\hline Artichoke & & & & & & \\
\hline Asparagus & & & & & & \\
\hline Aubergine & & & & & & \\
\hline Beetroot & & & & & & \\
\hline Broad beans & & & & & & \\
\hline Broccoli & & & & & & \\
\hline Brussel Sprout & & & & & & \\
\hline Butter beans & & & & & & \\
\hline $\begin{array}{l}\text { Butternut } \\
\text { Squash }\end{array}$ & & & & & & \\
\hline Cabbage & & & & & & \\
\hline Carrot & & & & & & \\
\hline Cauliflower & & & & & & \\
\hline Celery & & & & & & \\
\hline Chickpeas & & & & & & \\
\hline Courgette & & & & & & \\
\hline Cucumber & & & & & & \\
\hline Curly Kale & & & & & & \\
\hline Green beans & & & & & & \\
\hline Kidney beans & & & & & & \\
\hline Leek & & & & & & \\
\hline
\end{tabular}




\begin{tabular}{|c|c|c|c|c|c|c|}
\hline & \multicolumn{6}{|c|}{ How much does your child like this vegetable? } \\
\hline & Never Tried & $\begin{array}{l}\text { Strongly } \\
\text { Dislikes }\end{array}$ & Dislikes & $\begin{array}{c}\text { Neither Likes } \\
\text { Nor Dislikes }\end{array}$ & Likes & $\begin{array}{c}\text { Strongly } \\
\text { Likes }\end{array}$ \\
\hline Lentils & & & & & & \\
\hline Lettuce & & & & & & \\
\hline Mange-tout & & & & & & \\
\hline Marrow & & & & & & \\
\hline Mushroom & & & & & & \\
\hline Onion & & & & & & \\
\hline Parsnip & & & & & & \\
\hline Peas & & & & & & \\
\hline Pepper & & & & & & \\
\hline Pumpkin & & & & & & \\
\hline Radish & & & & & & \\
\hline Spinach & & & & & & \\
\hline Spring onion & & & & & & \\
\hline Sugar snap pea & & & & & & \\
\hline Swede & & & & & & \\
\hline Sweet potato & & & & & & \\
\hline Sweet corn & & & & & & \\
\hline Turnip & & & & & & \\
\hline Water cress & & & & & & \\
\hline
\end{tabular}


Please indicate how much YOUR CHILD likes the fruit named.

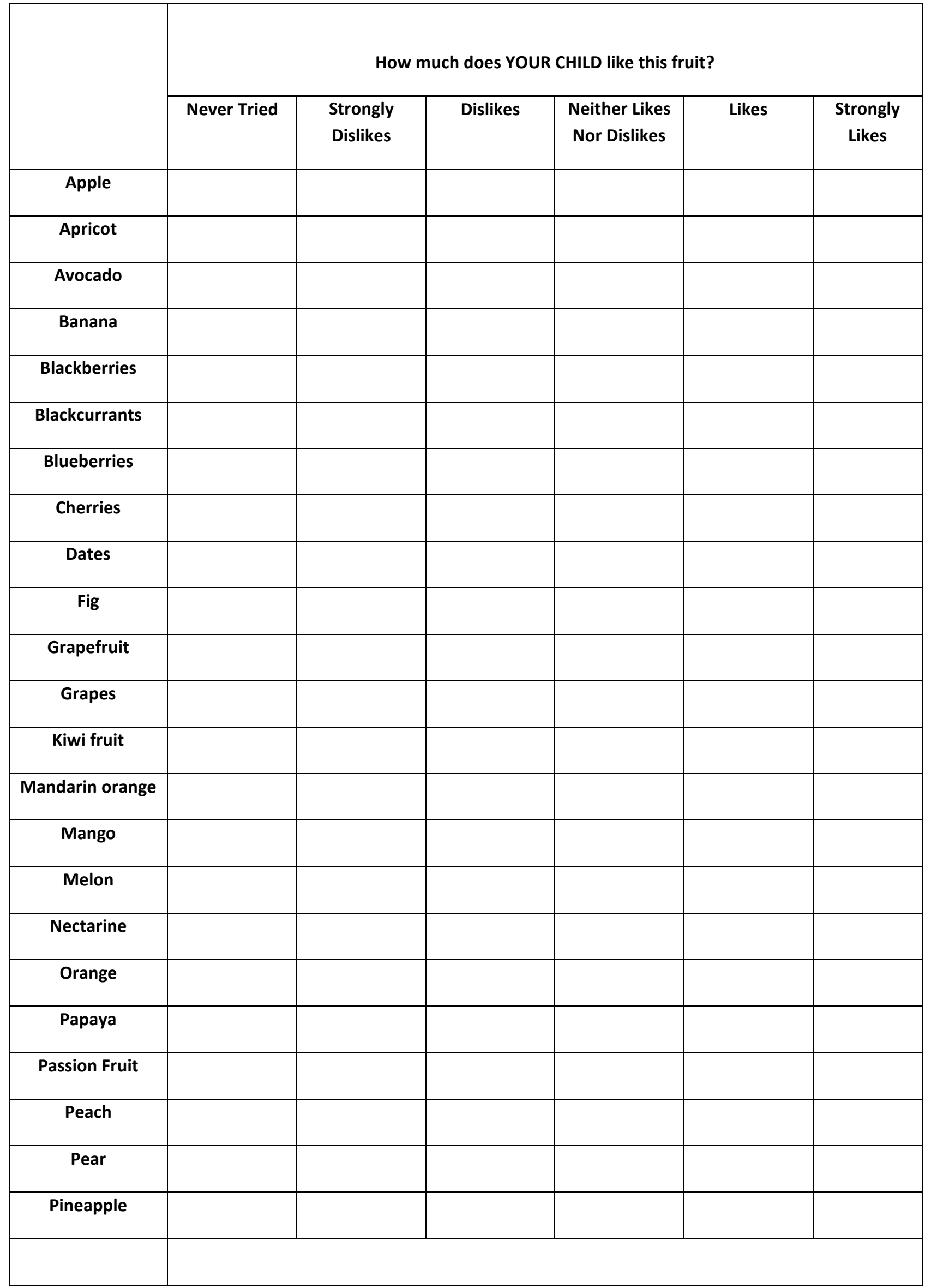




\begin{tabular}{|c|l|l|l|l|l|l|}
\hline \multirow{2}{*}{} & \multicolumn{5}{|c|}{ How much does YOUR CHILD like this fruit? } & \\
\cline { 2 - 6 } & Never Tried & $\begin{array}{c}\text { Strongly } \\
\text { Dislikes }\end{array}$ & Dislikes & $\begin{array}{c}\text { Neither Likes } \\
\text { Nor Dislikes }\end{array}$ & $\begin{array}{c}\text { Likes } \\
\text { Likes }\end{array}$ \\
\hline Plum & & & & & & \\
\hline Pomegranate & & & & & & \\
\hline Prunes & & & & & & \\
\hline Raspberries & & & & & & \\
\hline Rhubarb & & & & & & \\
\hline Sharon fruit & & & & & & \\
\hline Strawberries & & & & & & \\
\hline Sultanas & & & & & & \\
\hline Tomato & & & & & & \\
\hline Water Melon & & & & & & \\
\hline
\end{tabular}


Appendix II

Child Food Frequency Questionnaire

CFFQ

Please tell us how often YOUR CHILD consumes a portion of these fruits and vegetables.

For children, one portion is approximately the amount of food that would fit into the palm of your child's hand.

\begin{tabular}{|c|c|c|c|c|c|c|c|c|c|c|c|}
\hline FRUIT & $\begin{array}{c}\text { Never } \\
\text { or less } \\
\text { than } \\
\text { once/ } \\
\text { month }\end{array}$ & $\begin{array}{c}1-3 \\
\text { per } \\
\text { month }\end{array}$ & $\begin{array}{l}\text { Once } \\
\text { a } \\
\text { week }\end{array}$ & $\begin{array}{c}2 \\
\text { per } \\
\text { week }\end{array}$ & $\begin{array}{c}3 \\
\text { per } \\
\text { week }\end{array}$ & $\begin{array}{c}4 \\
\text { per } \\
\text { week }\end{array}$ & $\begin{array}{c}5 \\
\text { per } \\
\text { week }\end{array}$ & $\begin{array}{c}6 \\
\text { per } \\
\text { week }\end{array}$ & $\begin{array}{l}\text { Once } \\
\text { a } \\
\text { day }\end{array}$ & $\begin{array}{l}2 \\
\text { per } \\
\text { day }\end{array}$ & $\begin{array}{l}3+ \\
\text { per } \\
\text { day }\end{array}$ \\
\hline Apples & $\square$ & $\square$ & $\square$ & $\square$ & $\square$ & $\square$ & $\square$ & $\square$ & $\square$ & $\square$ & $\square$ \\
\hline Pears & $\square$ & $\square$ & $\square$ & $\square$ & $\square$ & $\square$ & $\square$ & $\square$ & $\square$ & $\square$ & $\square$ \\
\hline Oranges, Satsuma, Mandarin & $\square$ & $\square$ & $\square$ & $\square$ & $\square$ & $\square$ & $\square$ & $\square$ & $\square$ & $\square$ & $\square$ \\
\hline Bananas & $\square$ & $\square$ & $\square$ & $\square$ & $\square$ & $\square$ & $\square$ & $\square$ & $\square$ & $\square$ & $\square$ \\
\hline Grapes & $\square$ & $\square$ & $\square$ & $\square$ & $\square$ & $\square$ & $\square$ & $\square$ & $\square$ & $\square$ & $\square$ \\
\hline Melon & $\square$ & $\square$ & $\square$ & $\square$ & $\square$ & $\square$ & $\square$ & $\square$ & $\square$ & $\square$ & $\square$ \\
\hline Peaches, Plums, Apricots & $\square$ & $\square$ & $\square$ & $\square$ & $\square$ & $\square$ & $\square$ & $\square$ & $\square$ & $\square$ & $\square$ \\
\hline Strawberries, Raspberries, Kiwi fruits & $\square$ & $\square$ & $\square$ & $\square$ & $\square$ & $\square$ & $\square$ & $\square$ & $\square$ & $\square$ & $\square$ \\
\hline Tinned fruit (e.g. Peaches) & $\square$ & $\square$ & $\square$ & $\square$ & $\square$ & $\square$ & $\square$ & $\square$ & $\square$ & $\square$ & $\square$ \\
\hline Dried fruit (e.g. Raisins, Apricots) & $\square$ & $\square$ & $\square$ & $\square$ & $\square$ & $\square$ & $\square$ & $\square$ & $\square$ & $\square$ & $\square$ \\
\hline Fruit juice/ Smoothie (around 75ml) & $\square$ & $\square$ & $\square$ & $\square$ & $\square$ & $\square$ & $\square$ & $\square$ & $\square$ & $\square$ & $\square$ \\
\hline $\begin{array}{l}\text { Your child's target fruit: (please name \& } \\
\text { tell us how often your child eats this fruit) } \\
1 .\end{array}$ & $\square$ & $\square$ & $\square$ & $\square$ & $\square$ & $\square$ & $\square$ & $\square$ & $\square$ & $\square$ & $\square$ \\
\hline VEGETABLES & $\begin{array}{c}\text { Never } \\
\text { or less } \\
\text { than } \\
\text { once/ } \\
\text { month }\end{array}$ & $\begin{array}{c}1-3 \\
\text { per } \\
\text { month }\end{array}$ & $\begin{array}{l}\text { Once } \\
\text { a } \\
\text { week }\end{array}$ & $\begin{array}{c}2 \\
\text { per } \\
\text { week }\end{array}$ & $\begin{array}{c}3 \\
\text { per } \\
\text { week }\end{array}$ & $\begin{array}{c}4 \\
\text { per } \\
\text { week }\end{array}$ & $\begin{array}{c}5 \\
\text { per } \\
\text { week }\end{array}$ & $\begin{array}{c}6 \\
\text { per } \\
\text { week }\end{array}$ & $\begin{array}{l}\text { Once } \\
\text { a } \\
\text { day }\end{array}$ & $\begin{array}{c}2 \\
\text { per } \\
\text { day }\end{array}$ & $\begin{array}{l}3+ \\
\text { per } \\
\text { day }\end{array}$ \\
\hline Onions & $\square$ & $\square$ & $\square$ & $\square$ & $\square$ & $\square$ & $\square$ & $\square$ & $\square$ & $\square$ & $\square$ \\
\hline Peas & $\square$ & $\square$ & $\square$ & $\square$ & $\square$ & $\square$ & $\square$ & $\square$ & $\square$ & $\square$ & $\square$ \\
\hline Broccoli, Cauliflower & $\square$ & $\square$ & $\square$ & $\square$ & $\square$ & $\square$ & $\square$ & $\square$ & $\square$ & $\square$ & $\square$ \\
\hline Carrots & $\square$ & $\square$ & $\square$ & $\square$ & $\square$ & $\square$ & $\square$ & $\square$ & $\square$ & $\square$ & $\square$ \\
\hline Lettuce - mixed leaves & $\square$ & $\square$ & $\square$ & $\square$ & $\square$ & $\square$ & $\square$ & $\square$ & $\square$ & $\square$ & $\square$ \\
\hline Courgettes & $\square$ & $\square$ & $\square$ & $\square$ & $\square$ & $\square$ & $\square$ & $\square$ & $\square$ & $\square$ & $\square$ \\
\hline Mixed vegetables - frozen or tinned & $\square$ & $\square$ & $\square$ & $\square$ & $\square$ & $\square$ & $\square$ & $\square$ & $\square$ & $\square$ & $\square$ \\
\hline Tomato - puree, canned, fresh, sundried & $\square$ & $\square$ & $\square$ & $\square$ & $\square$ & $\square$ & $\square$ & $\square$ & $\square$ & $\square$ & $\square$ \\
\hline Mushrooms & $\square$ & $\square$ & $\square$ & $\square$ & $\square$ & $\square$ & $\square$ & $\square$ & $\square$ & $\square$ & $\square$ \\
\hline Peppers & $\square$ & $\square$ & $\square$ & $\square$ & $\square$ & $\square$ & $\square$ & $\square$ & $\square$ & $\square$ & $\square$ \\
\hline Sweet corn - baby, canned & $\square$ & $\square$ & $\square$ & $\square$ & $\square$ & $\square$ & $\square$ & $\square$ & $\square$ & $\square$ & $\square$ \\
\hline Cucumber, Celery & $\square$ & $\square$ & $\square$ & $\square$ & $\square$ & $\square$ & $\square$ & $\square$ & $\square$ & $\square$ & $\square$ \\
\hline Baked beans & $\square$ & $\square$ & $\square$ & $\square$ & $\square$ & $\square$ & $\square$ & $\square$ & $\square$ & $\square$ & $\square$ \\
\hline $\begin{array}{l}\text { Beans and pulses (e.g. kidney beans, } \\
\text { lentils, chickpeas) }\end{array}$ & $\square$ & $\square$ & $\square$ & $\square$ & $\square$ & $\square$ & $\square$ & $\square$ & $\square$ & $\square$ & $\square$ \\
\hline $\begin{array}{l}\text { Your child's target vegetable: (please } \\
\text { name and tell us how often your child eats } \\
\text { this target vegetable) } \\
\text { 1. }\end{array}$ & $\square$ & $\square$ & $\square$ & $\square$ & $\square$ & $\square$ & $\square$ & $\square$ & $\square$ & $\square$ & $\square$ \\
\hline
\end{tabular}


Appendix III

The number of times each fruit and vegetable was chosen by parents as a 'target' food

\begin{tabular}{|c|c|c|c|}
\hline Fruits & Frequency of selection & Vegetables & Frequency of selection \\
\hline Apple & 16 & Artichoke & 1 \\
\hline Apricot & 4 & Asparagus & 6 \\
\hline Avocado & 3 & Aubergine & 3 \\
\hline Banana & 11 & Broccoli & 23 \\
\hline Blueberries & 2 & Broad beans & 1 \\
\hline Cherries & 3 & Butternut squash & 2 \\
\hline Clementine & 2 & Cabbage & 4 \\
\hline Dates & 1 & Carrots & 21 \\
\hline Grapefruit & 1 & Cauliflower & 9 \\
\hline Grapes & 6 & Courgette & 5 \\
\hline Kiwi fruit & 8 & Cucumber & 9 \\
\hline Mango & 4 & Green beans & 7 \\
\hline Melon & 5 & Lettuce & 2 \\
\hline Nectarine & 2 & Mushroom & 3 \\
\hline Orange & 7 & Parsnip & 2 \\
\hline Papaya & 2 & Peas & 5 \\
\hline Passion fruit & 1 & Peppers & 3 \\
\hline Peach & 4 & Runner beans & 1 \\
\hline Pear & 5 & Spinach & 3 \\
\hline Pineapple & 10 & Sprouts & 1 \\
\hline Plum & 2 & Swede & 1 \\
\hline Pomegranate & 1 & Sweet potato & 1 \\
\hline Raspberries & 7 & Sweetcorn & 2 \\
\hline Satsuma & 4 & Tomato & 12 \\
\hline Strawberries & 12 & & \\
\hline Tomato & 4 & & \\
\hline Total & 127 & & 127 \\
\hline
\end{tabular}


Table 1. Demographic and background measures collected at baseline.

\begin{tabular}{|c|c|c|c|c|}
\hline \multirow[b]{2}{*}{$\begin{array}{l}\text { Measure (mean (SD), unless } \\
\text { otherwise indicated) }\end{array}$} & \multicolumn{3}{|c|}{ Experimental Group } & \multirow[b]{2}{*}{ Group Comparison } \\
\hline & $\begin{array}{l}\text { Fruit } \\
\text { Book }\end{array}$ & $\begin{array}{l}\text { Vegetable } \\
\text { Book }\end{array}$ & $\begin{array}{l}\text { Control } \\
\text { Group }\end{array}$ & \\
\hline Child age & $21.8(1.6)$ & $21.7(1.7)$ & $21.3(1.4)$ & $F(2,124)=1.32, p=.27$ \\
\hline Child gender (\% male) & 52.4 & 50.0 & 43.6 & $\chi^{2}(2)=.67, p=.72$ \\
\hline Child ethnicity (\% White & 85.7 & 82.6 & 82.1 & $\chi^{2}(2)=.24, p=.89$ \\
\hline \multicolumn{5}{|l|}{ British) } \\
\hline Parent education ( $\%$ degree) & 59.5 & 47.8 & 59.0 & $\chi^{2}(2)=1.55, p=.46$ \\
\hline Marital status (\% married) & 75.6 & 71.7 & 71.8 & $\chi^{2}(2)=.21, p=.90$ \\
\hline Household income $(\% £ 50 \mathrm{k}+$ & 55.0 & 50.0 & 41.7 & $\chi^{2}(2)=1.37, p=.51$ \\
\hline \multicolumn{5}{|l|}{ pa) } \\
\hline $\mathrm{N}$ children in home & $1.68(.69)$ & $1.76(.77)$ & $1.72(.83)$ & $F(2,122)=.10, p=.91$ \\
\hline Frequency of family meals & $12.2(4.0)$ & $13.6(3.6)$ & $12.3(4.5)$ & $F(2,116)=1.52, p=.22$ \\
\hline Weekly fruit purchases & $30.6(9.9)$ & $30.3(8.4)$ & $28.8(10.0)$ & $F(2,124)=.42, p=.66$ \\
\hline Weekly vegetable purchases & $40.0(11.2)$ & $36.9(11.1)$ & $36.8(9.2)$ & $F(2,124)=1.21, p=.30$ \\
\hline Target fruit purchases & $1.26(.11)$ & $1.28(.69)$ & $1.21(.80)$ & $F(2,124)=.13 p=.88$ \\
\hline Target vegetable purchases & $1.62(.62)$ & $1.58(.69)$ & $1.29(.80)$ & $F(2,122)=2.56, p=.08$ \\
\hline Child's daily fruit intake & $3.96(2.3)$ & $3.60(2.1)$ & $3.42(1.9)$ & $F(2,119)=.68, p=.51$ \\
\hline Child daily vegetable intake & $3.22(1.6)$ & $3.43(2.0)$ & $3.37(1.8)$ & $F(2,121)=.15, p=.86$ \\
\hline Child Food Neophobia score & $13.8(5.0)$ & $14.8(4.2)$ & $13.0(4.1)$ & $F(2,122)=1.69, p=.19$ \\
\hline Child Food Fussiness score & $16.1(4.8)$ & $17.4(4.4)$ & $15.5(4.4)$ & $F(2,123)=1.95, p=.15$ \\
\hline
\end{tabular}


Table 2. Mean number of days (SD) on which parents reported offering their child a taste of each target food, and on which children tasted it, during the 2-week taste exposure phase, by group

\section{Experimental Group}

\begin{tabular}{lcccc}
\hline & $\begin{array}{c}\text { Fruit } \\
\text { Book }\end{array}$ & $\begin{array}{c}\text { Vegetable } \\
\text { Book }\end{array}$ & $\begin{array}{c}\text { Control } \\
\text { Group }\end{array}$ & Group Comparison \\
\cline { 1 - 4 } N days fruit offered & $13.4(1.7)$ & $12.5(2.3)$ & $13.1(1.9)$ & $F(2,97)=1.77, p=.18$ \\
N days vegetable offered & $12.3(2.6)$ & $12.1(1.8)$ & $12.4(2.5)$ & $F(2,97)=.12, p=.89$ \\
N days fruit tasted & $8.5(4.8)$ & $7.8(4.9)$ & $7.5(5.3)$ & $F(2,97)=.32, p=.73$ \\
N days vegetable tasted & $6.6(4.8)$ & $7.8(4.3)$ & $6.3(4.4)$ & $F(2,97)=1.11, p=.33$ \\
\hline
\end{tabular}


Table 3. Mean ratings (SD) of children's liking and consumption of their target fruit and vegetable at baseline, post-intervention and follow-up, by experimental group

\section{Experimental Group}

\begin{tabular}{|c|c|c|c|c|}
\hline & Fruit Book & Vegetable Book & Control Group & \\
\hline \multicolumn{5}{|c|}{ Child's Liking of Target Fruit ${ }^{a}$} \\
\hline Baseline & $1.75(.65)$ & $1.93(.91)$ & $2.04(.79)$ & $1.91(.79)$ \\
\hline Post-intervention & $3.25(1.40)$ & $3.27(1.39)$ & $3.36(1.28)$ & $3.29(1.35)$ \\
\hline Follow-up & $3.11(1.49)$ & $3.41(1.40)$ & $3.16(1.28)$ & $3.28(1.35)$ \\
\hline \multicolumn{5}{|c|}{ Child's Liking of Target Vegetable $^{a}$} \\
\hline Baseline & $2.00(.71)$ & $1.74(.73)$ & $1.83(.66)$ & $1.85(.70)$ \\
\hline Post-intervention & $2.45(1.15)$ & $3.65(1.05)$ & $2.41(1.12)$ & $2.85(1.24)$ \\
\hline Follow-up & $2.50(1.15)$ & $3.30(1.26)$ & $2.63(1.21)$ & $2.87(1.30)$ \\
\hline \multicolumn{5}{|c|}{ Child's Consumption of Target Fruit ${ }^{b}$} \\
\hline Baseline & $.03(.09)$ & $.07(.17)$ & $.20(.59)$ & $.09(.35)$ \\
\hline Post-intervention & $.46(.50)$ & $.43(.53)$ & $.36(.41)$ & $.42(.48)$ \\
\hline Follow-up & $.11(.23)$ & $.15(.16)$ & $.12(.21)$ & $.13(.20)$ \\
\hline \multicolumn{5}{|c|}{ Child's Consumption of Target Vegetable ${ }^{b}$} \\
\hline Baseline & $.06(.13)$ & $.15(.46)$ & $.14(.38)$ & $.11(.35)$ \\
\hline Post-intervention & $.35(.37)$ & $.41(.43)$ & $.30(.35)$ & $.35(.38)$ \\
\hline Follow-up & $.15(.21)$ & $.27(.22)$ & $.11(.16)$ & $.18(.21)$ \\
\hline
\end{tabular}


Table 4. Regression table showing predictors of change in liking of the target vegetable from baseline to post-intervention.

\begin{tabular}{lccccc} 
& $\mathrm{B}$ & Std. Error B & $\beta$ & $\mathrm{t}$ & $\mathrm{p}$ \\
\hline Number of tastes (target vegetable) & .17 & .022 & .60 & 7.46 & .000 \\
Frequency of Family Meals & .10 & .026 & .31 & 3.81 & .000 \\
Group & .44 & .13 & .28 & 3.50 & .001 \\
\hline Excluded variables: & & & & .80 & .43 \\
CFNS scores & & & .01 & .99 \\
Total fruit purchases & & & & & \\
\hline
\end{tabular}

$R^{2}=.54, F(3,73)=27.97, p<.001$ 
Table 5. Regression table showing predictors of change in liking of the target vegetable from baseline to follow-up.

\begin{tabular}{lccccc} 
& $\mathrm{B}$ & Std. Error B & $\beta$ & $\mathrm{t}$ & $\mathrm{p}$ \\
\hline $\begin{array}{l}\text { Included variables: } \\
\text { Number of tastes (target vegetable) }\end{array}$ & .132 & .030 & .467 & 4.334 & .000 \\
Group & .350 & .161 & .235 & 2.176 & .033 \\
\hline
\end{tabular}

$R^{2}=.28, F(2,61)=13.32, p<.001$ 
Table 6. Regression table showing predictors of change in consumption of the target vegetable from baseline to post-intervention.

\begin{tabular}{lccccc} 
& $\mathrm{B}$ & Std. Error B & $\beta$ & $\mathrm{t}$ & $\mathrm{p}$ \\
\hline Included variables: & & & & & \\
Group & .106 & .035 & .34 & 3.07 & .003 \\
\hline Excluded variables: & & & 1.49 & .14 \\
CEBQ:FF scores & & 1.11 & .27 \\
N of tastes (target vegetable) & & & & \\
\hline
\end{tabular}

$R^{2}=.12, F(1,72)=9.42, p=.003$ 
Table 7. Mean reports (SD) of children's total daily fruit and vegetable intake and food neophobia and food fussiness scores at baseline, post-intervention and follow up, by group

\section{Experimental Group}

\begin{tabular}{|c|c|c|c|c|}
\hline & Fruit Book & Vegetable Book & Control Group & \\
\hline \multicolumn{5}{|c|}{ Total Daily Fruit Intake ${ }^{a}$} \\
\hline Baseline & $3.96(2.33)$ & $3.59(2.07)$ & $3.42(1.88)$ & $3.67(2.10)$ \\
\hline Post-intervention & $3.84(1.71)$ & $3.53(1.75)$ & $3.36(1.58)$ & $3.57(1.68)$ \\
\hline Follow-up & $3.42(1.98)$ & $3.20(0.91)$ & $3.21(1.75)$ & $3.27(1.58)$ \\
\hline \multicolumn{5}{|c|}{ Total Daily Vegetable Intake ${ }^{a}$} \\
\hline Baseline & $3.22(1.62)$ & $3.39(1.96)$ & $3.37(1.76)$ & $3.34(1.78)$ \\
\hline Post-intervention & $3.56(1.47)$ & $3.49(1.79)$ & $3.52(1.87)$ & $3.52(1.71)$ \\
\hline Follow-up & $3.41(1.48)$ & $3.30(1.37)$ & $2.98(1.67)$ & $3.22(1.50)$ \\
\hline \multicolumn{5}{|c|}{ Child Food Neophobia Scale Scores ${ }^{b}$} \\
\hline Baseline & $13.81(4.97)$ & $14.84(4.26)$ & $13.00(4.15)$ & $13.92(4.49)$ \\
\hline Post-intervention & $14.00(5.08)$ & $14.26(4.02)$ & $13.74(3.91)$ & $14.00(4.32)$ \\
\hline Follow-up & $13.64(4.84)$ & $13.26(3.21)$ & $15.38(4.59)$ & $14.15(4.29)$ \\
\hline \multicolumn{5}{|c|}{ Child Food Fussiness Scores ${ }^{c}$} \\
\hline Baseline & $16.07(4.79)$ & $17.42(4.45)$ & 15.47 (4.39) & $16.37(4.57)$ \\
\hline Post-intervention & $17.06(4.57)$ & $16.63(4.33)$ & $16.77(4.00)$ & $16.82(4.27)$ \\
\hline Follow-up & $15.82(5.13)$ & $15.44(3.45)$ & $17.41(4.82)$ & $16.28(4.52)$ \\
\hline
\end{tabular}


Figure 1. Example picture book targeting the vegetable broccoli.

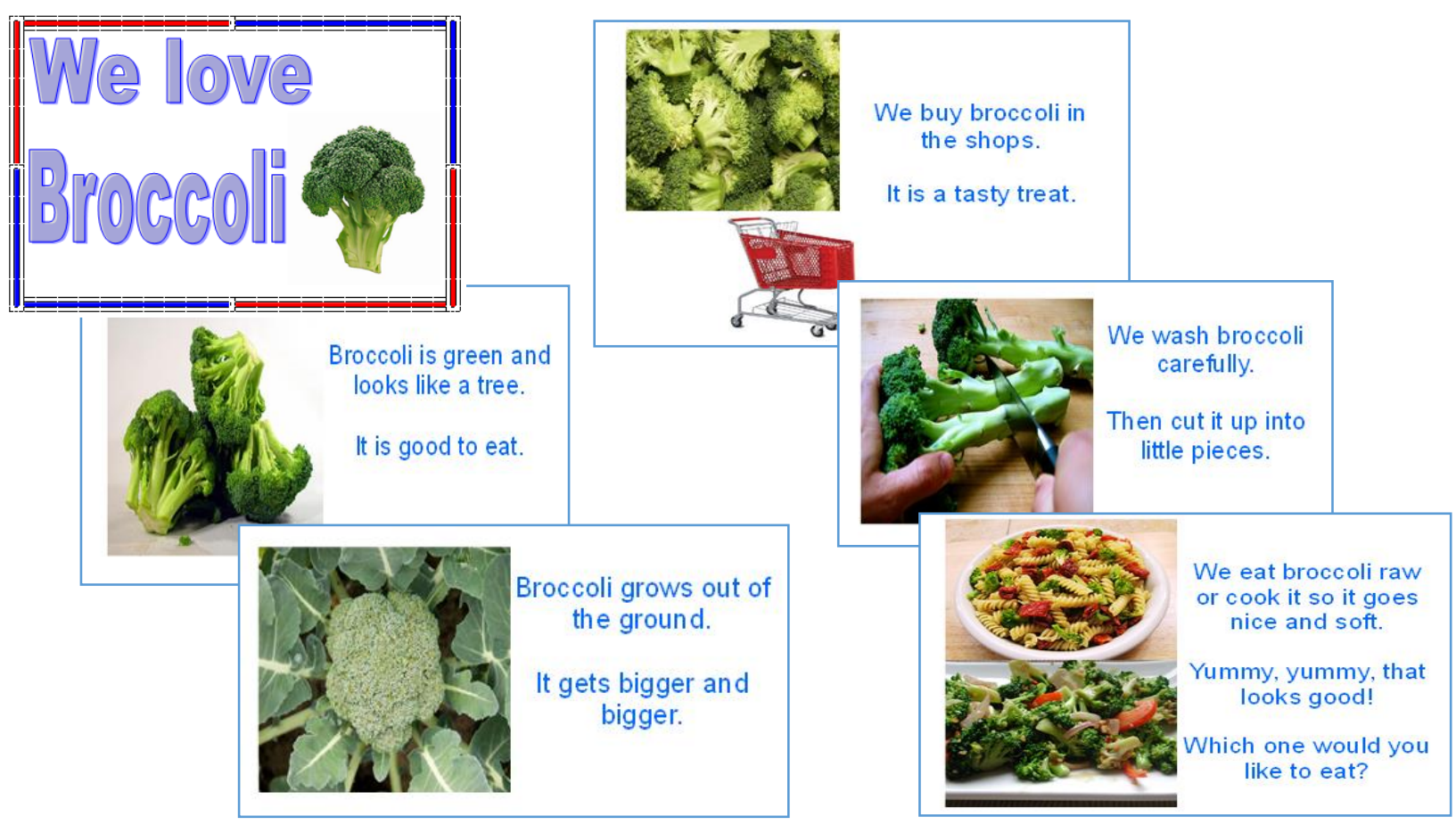


Figure 2. Mean reported liking of children's target fruit and vegetable (with standard error bars) at baseline, post-intervention and follow-up, by group

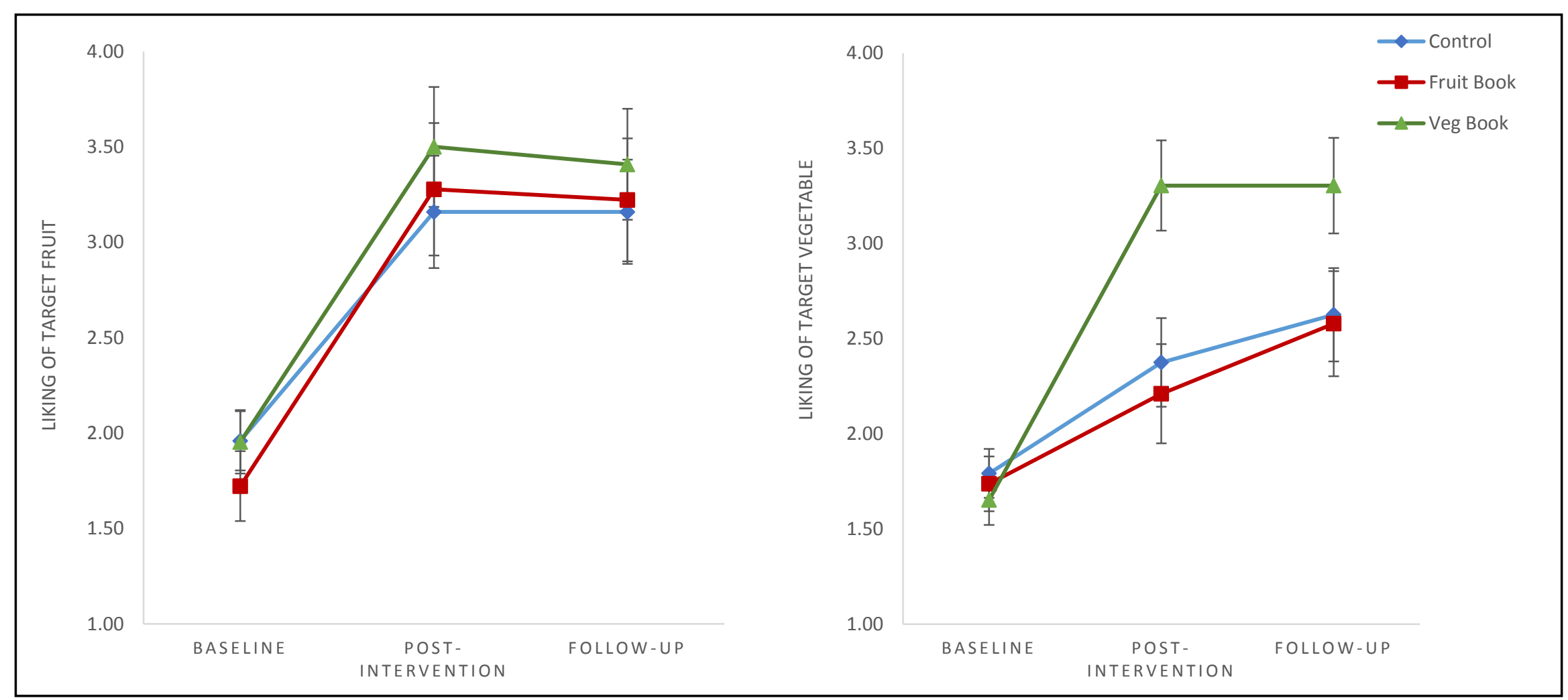


Figure 3. Mean reported consumption of the target fruit and vegetable (with standard error bars) at baseline and follow-up, by group. Consumption was reported in child-sized portions per day.

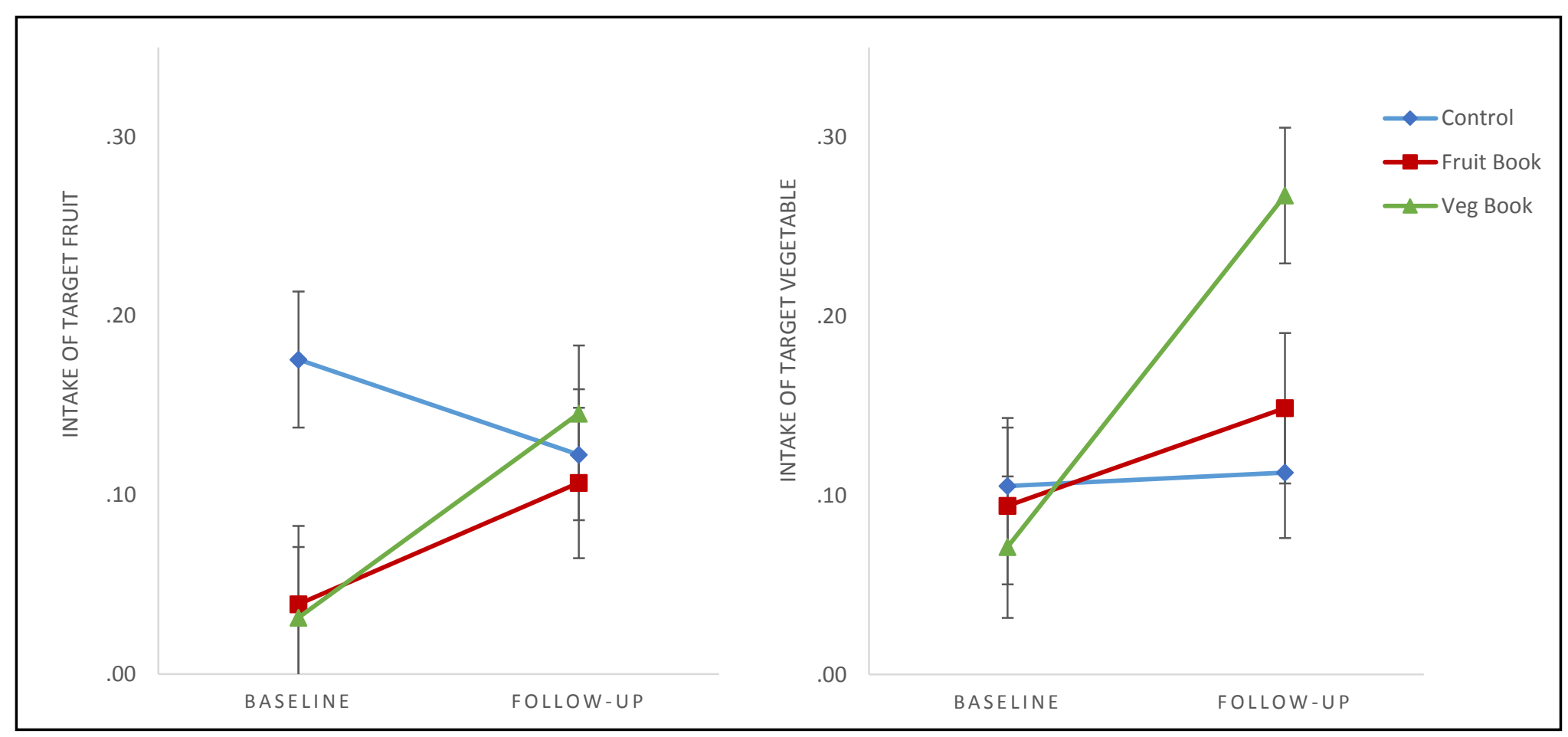


Figure 4. Mean scores (with standard error) on the Child Food Neophobia Scale (CFNS) and Food Fussiness subscale of Children's Eating Behaviour Questionnaire (CEBQ:FF) at baseline, post-intervention and follow-up, by group.

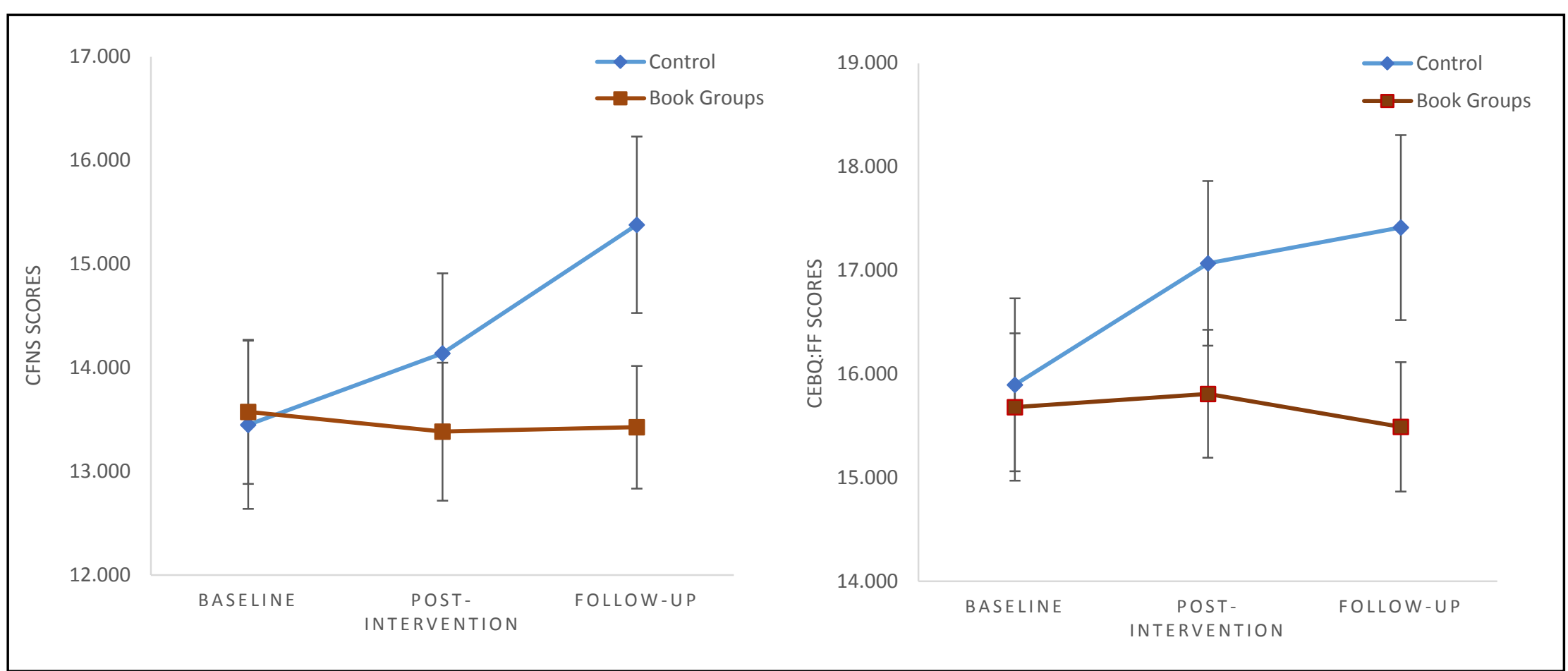

